\title{
Toward the sequence-based breeding in legumes in the post-genome sequencing era
}

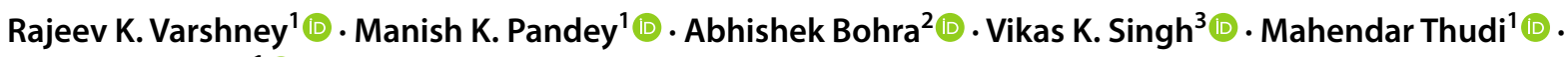 \\ Rachit K. Saxena' ${ }^{1}$
}

Received: 28 September 2018 / Accepted: 27 November 2018 / Published online: 17 December 2018

(c) The Author(s) 2018

\begin{abstract}
Efficiency of breeding programs of legume crops such as chickpea, pigeonpea and groundnut has been considerably improved over the past decade through deployment of modern genomic tools and technologies. For instance, next-generation sequencing technologies have facilitated availability of genome sequence assemblies, re-sequencing of several hundred lines, development of HapMaps, high-density genetic maps, a range of marker genotyping platforms and identification of markers associated with a number of agronomic traits in these legume crops. Although marker-assisted backcrossing and marker-assisted selection approaches have been used to develop superior lines in several cases, it is the need of the hour for continuous population improvement after every breeding cycle to accelerate genetic gain in the breeding programs. In this context, we propose a sequence-based breeding approach which includes use of independent or combination of parental selection, enhancing genetic diversity of breeding programs, forward breeding for early generation selection, and genomic selection using sequencing/genotyping technologies. Also, adoption of speed breeding technology by generating $4-6$ generations per year will be contributing to accelerate genetic gain. While we see a huge potential of the sequence-based breeding to revolutionize crop improvement programs in these legumes, we anticipate several challenges especially associated with high-quality and precise phenotyping at affordable costs, data analysis and management related to improving breeding operation efficiency. Finally, integration of improved seed systems and better agronomic packages with the development of improved varieties by using sequence-based breeding will ensure higher genetic gains in farmers' fields.
\end{abstract}

\section{Introduction}

Grain legumes such as chickpea (Cicer arietinum), pigeonpea (Cajanus cajan) and groundnut (Arachis hypogaea) are highly nutritious crops catering the dietary needs of several hundreds of million people across the world, especially in developing countries (Varshney et al. 2013c; Bohra et al. 2015a). Enormous health benefits associated with these crops earn them the title of "little marvels" (see Considine

Communicated by Lee Hickey.

Rajeev K. Varshney

r.k.varshney@ cgiar.org

1 International Crops Research Institute for the Semi-Arid Tropics (ICRISAT), Hyderabad 502324, India

2 ICAR-Indian Institute of Pulses Research (IIPR), Kanpur 208024, India

3 International Rice Research Institute (IRRI), IRRI South Asia Hub, ICRISAT, Hyderabad 502324, India
2016). Special features of these crops like symbiotic nitrogen fixation and improving soil health encourage inclusion in cropping systems, thus contributing to diversity and sustainability of the system. Sustainable development goals of United Nations seek contribution of grain legume crops particularly concerning malnutrition, income of small-scale food producers and sustainable food production systems (http://gh.one.un.org/content/unct/ghana/en/home/globa 1-agenda-in-ghana/sustainable-development-goals/SDG-2zero-hunger.html). Although grain legumes are indispensable for global food security and ecosystem resilience, these crops lagged behind cereals in their genetic improvement due to negligence in policy, low investment and lack of genomic resources essential for deploying advanced breeding technologies. Despite these constraints, recognizing the importance of grain legumes in human diet, animal feed and soil health, some efforts were made in the recent past to improve the yield and nutritional quality of legume crops in addition to employing improved agronomy and crop rotation approaches. Indeed, several hundreds of varieties and a few 
hybrids have been developed in the legume crops using conventional breeding methods for traits such as drought, heat, herbicide, low phosphorus tolerance, early maturity, insect resistance, machine harvestability and high nitrogen fixation (http://www.icrisat.org/impact-of-release-of-256-newlegume-and-119-dryland-cereal-varieties-and-hybrids-in40-countries-reviewed/). Nevertheless, the rate of genetic gains using the conventional approaches could not bridge the gap between the growing demands (Varshney et al. 2018) which is evident from only $60 \%$ increase in pulse production in last 50 years (Foyer et al. 2016).

Low genetic diversity in the breeding programs, lengthy crop breeding cycles, slower adoption of innovative breeding technologies and limited availability of quality seeds to farmers have been the major limitations in delivering higher genetic gains in farmers' field (Varshney et al. 2018). For instance, $50 \%$ of the genetic base of public pigeonpea cultivars is accounted for six founder genotypes (Saxena et al. 2018b). To expedite the breeding cycles, a range of low-tomoderate-scale genomic resources were developed in these crops during the last decade (Varshney et al. 2013c; Pandey et al. 2016). These resources enabled greater understanding of available genetic diversity as well as simplifying complex traits (Varshney et al. 2015). A range of molecular markers (mostly simple sequence repeats, SSRs), bi-parental and natural populations were used for trait dissection and trait improvement (Pandey et al. 2012; Thudi et al. 2014; Varshney 2016). As a result, like cereals, improved lines with enhanced resistance/tolerance to biotic or abiotic stresses, improved agronomic and nutritional traits have been developed in important grain legumes like chickpea and groundnut using marker-assisted backcrossing (MABC) (Pandey et al. 2016; Varshney 2016). Nevertheless, MABC approaches, in general, are successful only for introgression of major effect quantitative trait locus (QTL) or few genes.

The latest sequencing efforts motivated largely by nextgeneration sequencing (NGS) technologies have culminated in the availability of the reference genomes and re-sequencing of the germplasm and breeding lines in chickpea (Varshney et al. 2013b), pigeonpea (Varshney et al. 2012) and groundnut (Bertioli et al. 2016; Chen et al. 2016). This postgenome sequencing era also witnessed a paradigm shift from marker-based genotyping to sequencing-based genotyping of the breeding populations and diversified germplasm panels. Such efforts have facilitated development of highdensity genome/haplotype maps, identification of QTLs and discovery of new genes in several legume crops (Singh et al. 2016a; Pandey et al. 2017b; Singh et al. 2017). Furthermore, deployment of genomic technologies has yielded better breeding outcomes, with a range of molecular breeding products ready for testing and release. This primarily includes targeted improvement in disease resistance (Varshney et al. 2013a, 2014a, b; Kolekar et al. 2017), quality traits (Janila et al. 2016a; Bera et al. 2018) and resilience to changing climatic scenarios (Varshney et al. 2013a).

In the present article, we discuss the technological advances that led grain legumes into the post-genome sequencing era. We provide an update on the molecular breeding products ready for commercial cultivation in these crops. Special emphasis has been placed on potential and challenges in application of sequence-based methods in future breeding programs, and challenges that lie ahead are highlighted.

\section{Genome sequences}

Taking advantage of NGS technologies, draft genomes have been developed for chickpea (Varshney et al. 2013b), pigeonpea (Varshney et al. 2012) and groundnut or peanut (Bertioli et al. 2016; Chen et al. 2016). In chickpea, a high-yielding medium seeded kabuli variety CDC Frontier was used to develop the draft genome comprising $544.73 \mathrm{Mb}$ assembled sequence data representing $73.8 \%$ of the total chickpea genome (738.09 Mb) (Varshney et al. 2013b). In the case of pigeonpea, a high-yielding variety Asha (ICPL 87119) was used to generate $237.2 \mathrm{~Gb}$ of sequence data. A total of $605.78 \mathrm{Mb}$ could be assembled into scaffolds representing $\sim 73 \%$ of pigeonpea genome (Varshney et al. 2012). In groundnut, genome sequences of its diploid ancestors (A and B genomes) were reported. Sequencing of A-genome progenitor, A. duranensis (V14167 and PI475845), and B-genome progenitor A. ipaensis (K30076) was completed (Bertioli et al. 2016; Chen et al. 2016). A total of $96.0 \%$ and $99.2 \%$ of the sequence, represented by 1692 and 459 scaffolds, could be ordered into 10 pseudomolecules per genome of 1025 and $1338 \mathrm{Mb}$ for A. duranensis and A. ipaensis, respectively. Most recently, the high-quality reference genomes were also developed for two subspecies hypogaea (https://peanutbase .org/peanut_genome) and fastigiata (http://peanutgr.fafu.edu. $\mathrm{cn} /$ News_english.php) of cultivated tetraploid. These reference genomes are facilitating comparative and functional genomics studies in addition to genomics-assisted breeding (GAB) in these important legume crops.

\section{Highlights of three legume draft genomes}

The GC contents in all the three mentioned legume genomes were found to be in similar range as $30.78 \%$ in chickpea, $32.8 \%$ in pigeonpea and $31.79 \%$ in groundnut. On the other hand, a number of genes varied significantly in all the three legumes. Within the legumes, pigeonpea and chickpea belong to another sub-classification of pulse crops. These two pulse crops have also shown fold differences in terms of genes identified $(48,680$ genes in pigeonpea and 28,269 genes in chickpea). In case of groundnut, 50,324 genes (Chen et al. 2016) and 36,734 genes (Bertioli et al. 
2016) were identified in A. duranensis, while 41,840 genes in A. ipaensis (Bertioli et al. 2016). The soon to be available details of tetraploid genome assemblies of groundnut will have more precise and accurate information (personal communications with Scott Jackson, USA; Weijian Zhuang, China; and Xiaoping Chen, China). The huge differences in number of genes identified across three legumes and also within the groundnut genomes may be due to varying quality of the draft genome assemblies as well as different parameters/resources used for gene prediction. We understand that the genome assemblies will be improved with $\mathrm{Hi}-\mathrm{C}$ based sequencing technology (van Berkum et al. 2010), and then, the huge difference in number of genes may be reduced. The repetitive sequences composed of transposable elements and unclassified repeats in the three legume genomes also varied with $51.67 \%$ in pigeonpea, $49.41 \%$ in chickpea and $61.7 \%$ (A. duranensis) to $68.5 \%$ (A. ipaensis) in groundnut. The reference genomes developed for these three legumes have also been analyzed for crop specific traits, which in turn has facilitated understanding of the genetic variations found in each crop/genotype. For instance, 90 cultivated and wild genotypes from 10 different countries were also re-sequenced in the chickpea draft genome study. Comprehensive analysis of re-sequenced data provided targets of both breeding-associated genetic sweeps and domestication. Further, candidate genes in chickpea genome for disease resistance and agronomic traits have also been identified (Varshney et al. 2013b). Pigeonpea was the second legume crop after soybean and the first non-industrial legume crop with draft genome sequence available in 2012 (Varshney et al. 2012). Draft genome of pigeonpea also provided information on the role of potential gene families in evolution/ domestication, e.g., drought tolerance. In groundnut, Bertioli et al. (2016) provided insights into architecture and evolution of subgenomes, genetic exchange between subgenomes and candidate genes for disease resistance, whereas Chen et al. (2016) provided insights into geocarpy, oil biosynthesis and allergens besides providing information about evolution and polyploidization.

\section{Whole genome re-sequencing}

Availability of draft genomes has provided opportunities to deploy whole genome re-sequencing (WGRS)-based approaches in these three legumes. However, it was decided to move forward in a step-wise manner depending on the resources available. Therefore, in these legumes, different sets of genotypes/lines/accessions were selected based on their priority in respective crop improvement programs. As the first step in pigeonpea and chickpea, parents of segregating mapping populations were subjected to WGRS (Kumar et al. 2016; Thudi et al. 2016b). These studies have developed the first-generation HapMaps, signature sequences and large-scale variations for high-resolution trait mapping in pigeonpea and chickpea. Further, reference sets representing diversity present in genetic stocks available in gene bank were targeted for WGRS in pigeonpea (Varshney et al. 2017), chickpea (unpublished) and groundnut (unpublished). In the case of pigeonpea, WGRS data on reference set collection of 292 lines deduced the origin, migration of the crop and identified markers associated with traits of interest for crop improvement (Varshney et al. 2017). In parallel, 104 parental lines of hybrids in pigeonpea (unpublished) and 129 chickpea varieties/elite lines have been sequenced (Thudi et al. 2016a). Detailed analysis of WGRS data on 129 chickpea varieties/elite lines has provided temporal diversity trends across different time zones (Thudi et al. 2016a). Further, the 3000 Chickpea Genome Sequencing Initiative and sequencing of $>100$ wild species accessions in pigeonpea have been initiated recently. Approximately 40 lines in groundnut (Pandey et al. 2017a) have also been re-sequenced which include four synthetic tetraploids and their six diploid parents (Chen et al. 2016). Furthermore, sequencing of 300 genotypes of groundnut reference set is underway at ICRISAT for understanding the diversity, and population structure in the germplasm as well as for candidate gene discovery through genome-wide association studies (GWAS).

In summary, the draft genome sequence and re-sequencing data in all three legumes have provided information on genes/genomic segments involved in evolution, domestication, architecture, response to stresses, etc. The WGRS data have also provided access to the unique alleles, signature sequences, and markers and so on for research community. It is important to note that research advances made in these three legumes have also facilitated/motivated/supported other crop species as well. For instance, the pigeonpea genome sequence has been helpful to clone the resistance gene to Asian soybean rust disease that has been only treatable with fungicides in soybean (Kawashima et al. 2016).

\section{Appropriate genotyping assays for trait mapping and breeding}

The sequencing and re-sequencing of diverse germplasm make unlimited genome-wide structural variations available, which facilitate genotyping the genetic and breeding material. A number of marker genotyping platforms from low to high throughput have been deployed during last two decades in crop breeding (Rasheed et al. 2017).

In the case of these legume crops, there is mainly a need of following type of platforms for genetic analysis and breeding applications: (1) high-density genotyping (>20 K SNPs) of genetic populations for trait mapping using GWAS, (2) medium-density genotyping (2-5 K SNPs) of mapping populations for trait mapping using genetic mapping 
approach as well as for deploying genomic selection (GS) and (3) low-density genotyping (1-10 SNPs) for performing early generation screening as well as for marker-assisted selection, quality control (QC) and hybrid purity testing. To cater the above-mentioned needs, Axiom ${ }^{\circledR}$ Arrays with more than $50 \mathrm{~K}$ SNPs have been developed in chickpea (Roorkiwal et al. 2018a), pigeonpea (Saxena et al. 2018a, b, c) and groundnut (Pandey et al. 2017a). Sequencing-based genotyping approaches such as genotyping-by-sequencing (GBS), RADseq and skim sequencing have also been deployed in these legumes for genetic analysis and breeding applications. Initially, the genomic selection has been performed using GBS and subsequently with the SNP arrays (see Crossa et al. 2017). These analyses indicate that high-density genotyping is not always required for undertaking GS breeding. Therefore, efforts have been started to develop medium-density genotyping assays for uniformly distributed 2000-5000 high informative SNPs for deployment in GS breeding. In this direction, in collaboration with Cornell University and Integrated DNA Technologies company (https://www. idtdna.com/pages/products/qpcr-and-pcr/genotyping/rhamp -snp-genotyping), rhAmp SNP genotyping assays are being developed for about 2000 loci in each of the legume crops.

Regarding low-density genotyping assays, 10-SNP panels have been developed in collaboration with Intertek company for many crop species, including these three legume crops, for performing foreground selection in early generations of breeding program under the high-throughput genotyping project (HTPG) (Varshney 2016, http://cegsb.icrisat.org/ high-throughput-genotyping-project-htpg/). This technology is much cheaper as it just costs US\$1.5-2.0/sample for 10 SNP markers including DNA isolation. This low density or panel of selected genotyping has made task easier for breeding units either located remotely or units without DNA isolation facility. Such small SNP panels are more likely to be developed in future to perform specific tasks such as early generations screening, ensuring seed purity in seed lots and in identifying true $\mathrm{F}_{1}$ plants in routine breeding programs.

\section{Sequencing-based trait mapping}

Until 2005, most of these legume crops were facing problems for achieving even low-density genetic mapping due to paucity of polymorphic markers (Pandey et al. 2016; Varshney 2016). Several efforts for trait mapping made in these legume crops could achieve sparsely dense genetic maps, which did not allow genetic mapping at high resolution. Majority of these studies deployed large-scale SSR markers for checking polymorphism among parental genotypes, resulting in identification of limited number of polymorphic SSRs due to low level of polymorphism in cultivated gene pool. After the genome sequencing/re-sequencing data have become available in these legume crops in the last decade, millions of structural variations have been identified which can now be used as genetic markers in trait mapping and breeding. Currently, NGS-based high-throughput genotyping approaches are being deployed in these legumes that offer several advantages over earlier genotyping approaches. The major advantages include time-efficient and faster discovery of genomic regions and candidate genes for downstream applications such as gene cloning and molecular breeding research. The sequencing-based trait mapping can be accomplished by: (i) sequencing all individuals from an experimental population or diversified germplasm panel and (ii) sequencing the pooled samples of extremes phenotypes. These two approaches are now routinely deployed, and several such studies will be completed in coming years (Tables 1 and 2).

\section{Sequencing entire genetic populations}

The low-cost sequencing has encouraged researchers for sequencing complete genetic populations such as bi-parental (RIL recombinant inbred line), multi-parents (MAGIC multi-parent advanced generation inter-cross and NAM nested association mapping) and natural populations (different types of diversity panels and training sets). For sequencing an entire population, the sequencing data can be generated with either high coverage (using WGRS) or at low coverage (using GBS and skim sequencing). These genome-wide approaches provide highly informative SNPs at massive scale, which are crucial for high-density genetic mapping, and to facilitate understanding of genetic structures and to perform high-resolution trait mapping.

The sequencing-based genotyping of complete genetic populations or diverse germplasm set has yielded exciting results in several crop species. Notable examples include identification of candidate genomic region/gene and markertrait-associations through GWAS in rice (Huang et al. 2009). Sequencing-based genotyping has also been undertaken for mapping flowering time control, seed development and pod dehiscence in pigeonpea (Varshney et al. 2017), drought tolerance-related traits in chickpea (Kale et al. 2015) and resistance to early leaf spot, late leaf spot (LLS) and tomato spotted wilt virus (TSWV) in groundnut (Agarwal et al. 2018). For instance, in the case of groundnut, the WGRS of the complete RIL population identified two QTLs for early leaf spot (ELS) on B05 (47.42\% PVE) and B03 (47.38\% PVE); and two QTLs for LLS resistance on A05 (47.63\% PVE) and B03 (34.03\% PVE), while one QTL for TSWV resistance on B09 (40.71\% PVE) chromosomes (Agarwal et al. 2018). This study also identified candidate genes that were converted into Kompetitive allele-specific PCR (KASP) markers.

In the case of WGRS of diverse germplasm panel, 292 lines of pigeonpea reference set were used for the 


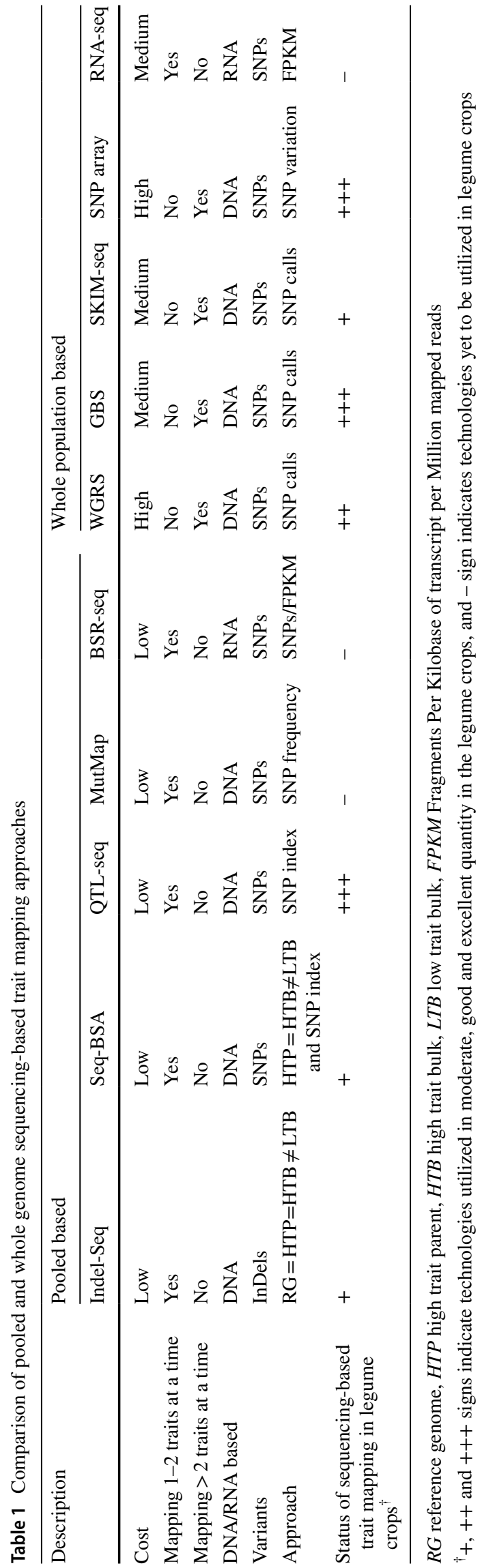

identification of candidate genes for flowering time control, seed development and pod dehiscence using GWAS approach (Varshney et al. 2017). Similar attempts on resequencing of diverse germplasm panel and GWAS are in progress in chickpea and groundnut. For example, the ICRISAT with its partners have made significant progress through "The 3000 Chickpea Genome Sequencing Initiative" (Varshney 2016) in sequencing and further analyzing the data for understanding the population structure and breeding history, and discovery of marker-trait associations and candidate genes for important agronomic traits. More such examples are likely to follow in coming years in these legume crops.

The GBS, another sequencing-based genotyping approach, was deployed in several studies in crops including legumes to discover a large number of genome-wide SNPs for conducting diverse genetic studies such as understanding genetic diversity and population structure, developing highdensity genetic maps, QTL analysis, GWAS and genomic selection (GS) (Elshire et al. 2011). The popularity and wider acceptability among researchers for GBS have been due to its cost-effectiveness with the greater scope to implement even in those crops where reference genome is not available. In chickpea, the GBS approach was deployed for studying molecular and genetic diversity, understanding the genetic architecture, population structure and linkage disequilibrium decay in cultivated and wild accessions (Bajaj et al. 2015; Kujur et al. 2015; Pavan et al. 2017). Further, the GBS or double-digest restriction-site-associated DNA sequencing (ddRADseq) facilitated construction of dense genetic maps in chickpea (Deokar et al. 2014; Jaganathan et al. 2015; Kujur et al. 2015; Verma et al. 2015); pigeonpea (Saxena et al. 2017a, b, 2018a) and groundnut (Zhou et al. 2014; unpublished).

An interesting example of use of GBS approach includes saturation of the "QTL-hotspot" region that harbors QTLs for several drought tolerance relevant traits. This study showed successful narrowing down of the genomic region from 29 to $14 \mathrm{cM}$ (Jaganathan et al. 2015). Similarly, 20 QTLs and candidate genes associated with seed traits were also identified in chickpea using GBS approach in another study (Pavan et al. 2017). In pigeonpea, the GBS-based mapping of two RIL populations led identification of QTLs and candidate genes for resistance to fusarium wilt (FW) and sterility mosaic disease (SMD) (Saxena et al. 2017a, b) in addition to restoration of fertility (Rf) (Saxena et al. 2018a). Similar attempts have been made in groundnut to employ GBS that has led to the identification of major QTLs and candidate genes for foliar disease namely late leaf spot (LLS) and rust resistance (Pandey et al. 2016; unpublished). Deployment of ddRADseq on the other hand yielded mere small-effect QTLs for LLS and other plant-type-related traits in groundnut (Zhou et al. 2016). Additionally, the GBS and 


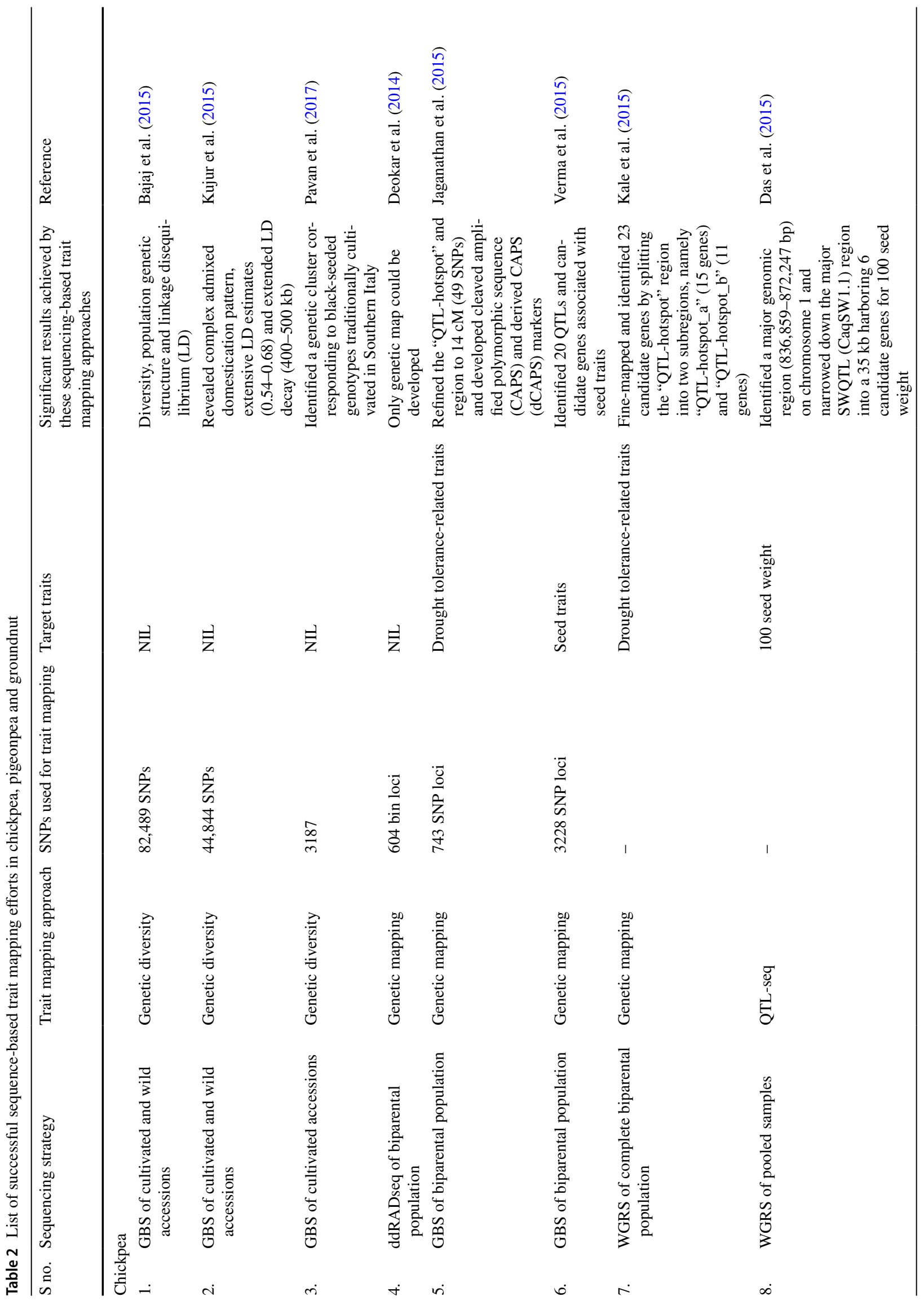




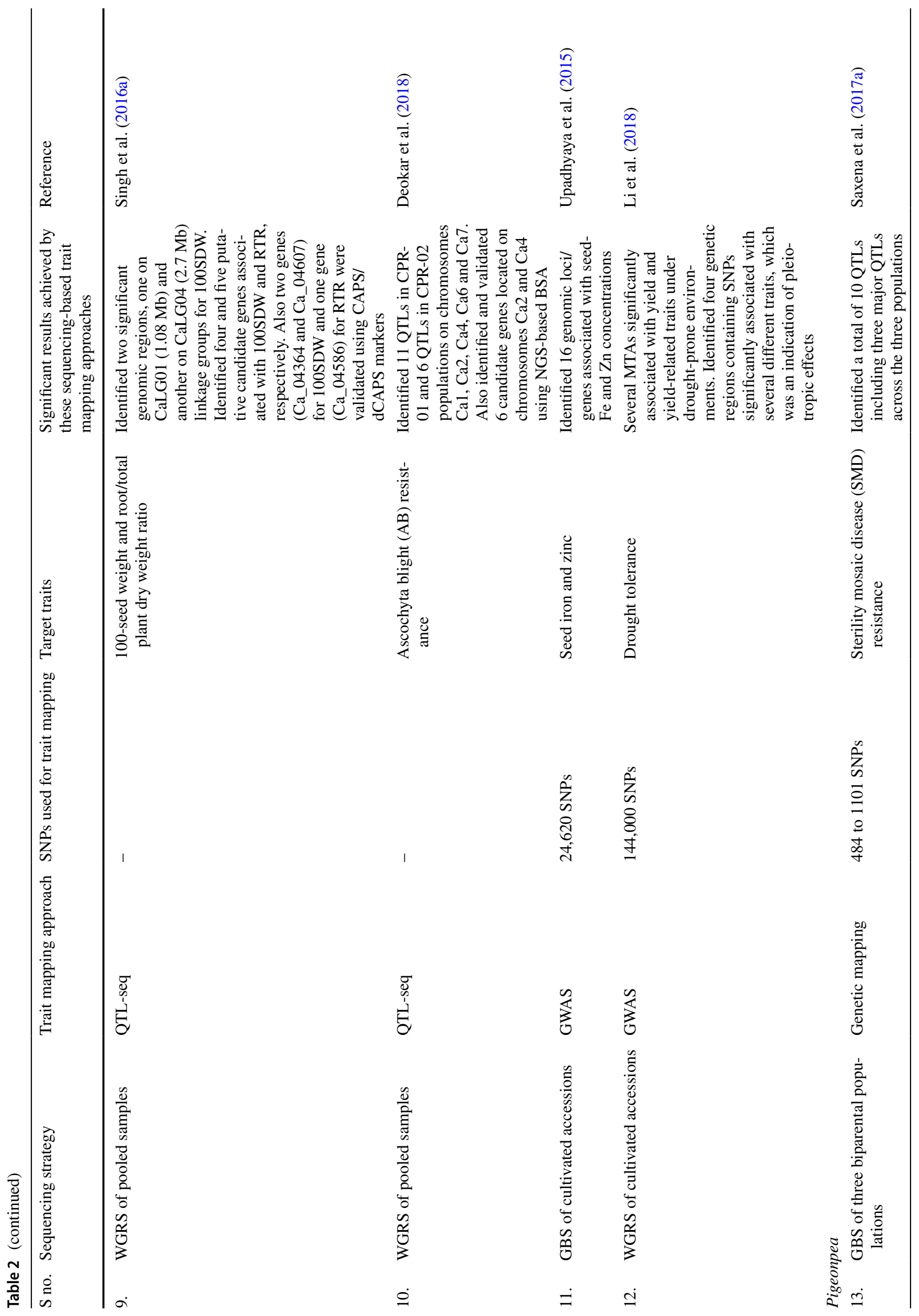




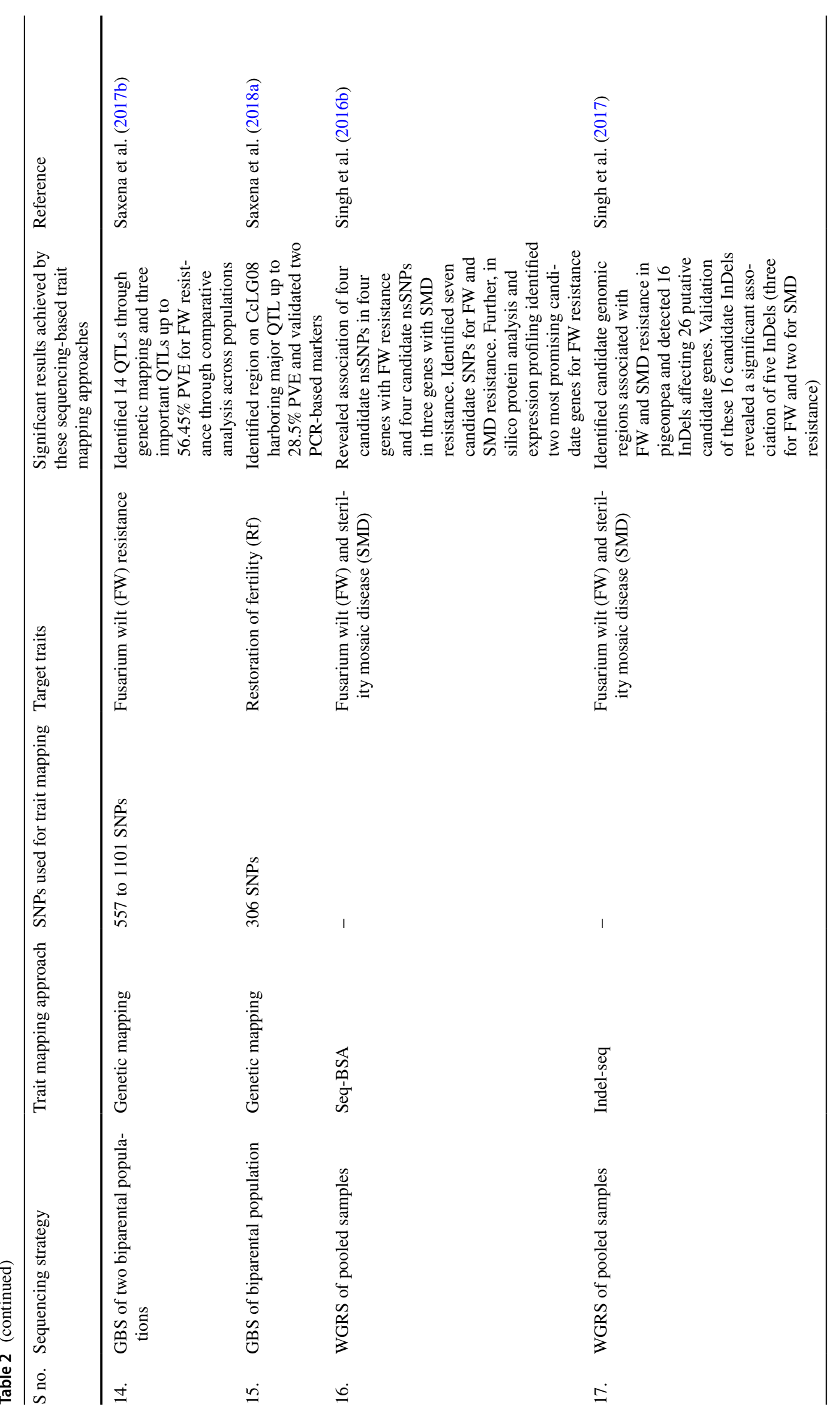



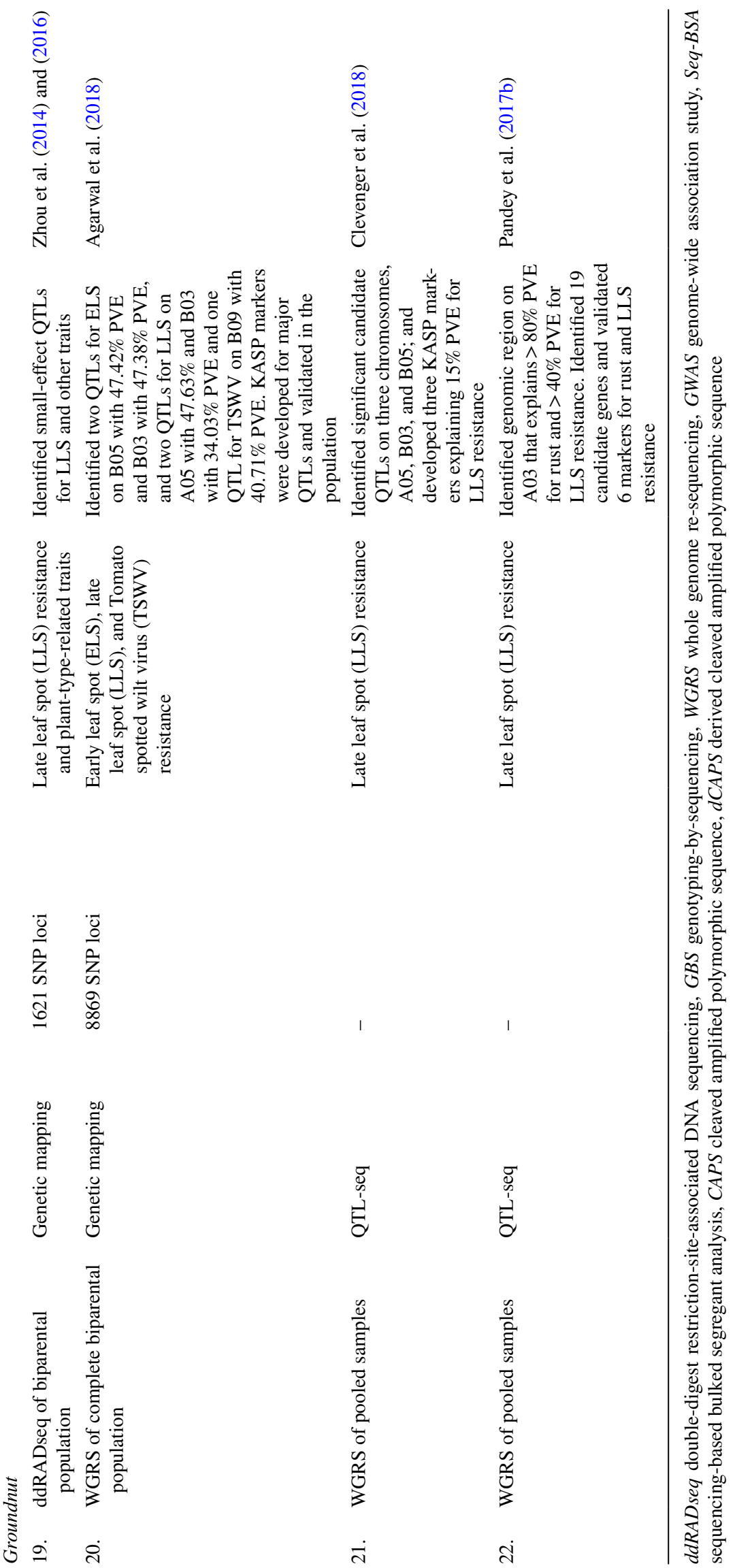
skim sequencing approaches have also played key role in improving genome assemblies in chickpea (Ruperao et al. 2014) making them more precise for conducting legume biology and comparative genomics studies (Table 2).

Both above-mentioned approaches, i.e., WGRS and GBS, have limitations and choice of using one approach over the other relies upon the objective of the study (requirement of more vs less markers), nature of genetic material as well as availability of funding resources and technical expertise. For example, the WGRS provides high-quality sequencing data, but it becomes unaffordable if the population is exceptionally large. On the other hand, the GBS generates considerably high number of missing data points across the population at a given locus that may be fine with genetic diversity or linkage mapping but is not deemed suitable for GS breeding. If the genome sequence is not available for a crop, GBS approach can still be used for SNP discovery. However, majority of legume crops including three mentioned legume crops have genome sequence assemblies available. The limitations of both of these approaches partly can be countered by performing sequencing at lower depth, referred as skim sequencing (Golicz et al. 2015). The utility of this approach has been demonstrated in fine mapping of the "QTL-hotspot" region for drought tolerance-related traits in chickpea (Kale et al. 2015). This study not only delineated the QTL region but also identified 23 candidate genes through resolving the "QTL-hotspot" region into two subregions namely "QTL-hotspot_a" $(139.22 \mathrm{~Kb} ; 15$ genes) and "QTL-hotspot_b" (153.36 Kb; 11 genes) (Kale et al. 2015).

\section{Sequencing extreme pools}

This latest trait mapping approach relies on sequencing of pooled samples constituted with RILs of extreme phenotype for a given trait that borrows the basic principle of bulked segregant analysis (BSA) (Michelmore et al. 1991). This principle can be applied in different types of bi-parental populations generated either by crossing two contrasting genotypes or by crossing the mutant with the original parent (wild type). Depending on the diverse origin and method of population development, these approaches have been referred to as QTL-Seq (Takagi et al. 2013a), SeqBSA (Singh et al. 2016a, b), Indel-Seq (Singh et al. 2017), MutMap (Abe et al. 2012), and BSR-Seq (Liu et al. 2012) approaches.

The "QTL-Seq" approach has been deployed in all these three legumes, i.e., in chickpea (Das et al. 2015; Singh et al. 2016a; Deokar et al. 2018), pigeonpea (Singh et al. 2016a) and groundnut (Pandey et al. 2017b; Clevenger et al. 2018). In the case of chickpea, this approach successfully identified a major genomic region $(836,859-872,247 \mathrm{bp})$ on Ca1 chromosome which was then further narrowed down to a $35-\mathrm{kb}$ region harboring six candidate genes for 100 seed weight (Das et al. 2015). Similarly, another such study in chickpea identified two significant genomic regions on $\mathrm{Ca} 1$ $(1.08 \mathrm{Mb})$ and $\mathrm{Ca} 4(2.7 \mathrm{Mb})$ chromosomes for 100 seed weight (100 SDW) leading to further discovery of four and five putative candidate genes associated with 100SDW and root traits ratio, respectively (Kale et al. 2015). This study also developed and validated CAPS/dCAPS markers for use in molecular breeding. Another research in chickpea identified 17 QTLs from two populations on five chromosomes (Ca1, Ca2, $\mathrm{Ca} 4, \mathrm{Ca} 6$ and $\mathrm{Ca} 7)$, of which six candidate genes on chromosomes $\mathrm{Ca} 2$ and $\mathrm{Ca} 4$ were further validated using NGS-based BSA. In case of pigeonpea, this approach was successfully deployed for localization of genomic regions and discovery of candidate genes for days to flowering and obcordate leaf shape (unpublished). In case of groundnut, deployment of QTL-seq approach identified genomic region on A03 chromosome that explains $>80 \%$ PVE for rust and $>40 \%$ PVE for LLS resistance, followed by the discovery of 19 candidate genes (Pandey et al. 2017b). This study also reported validation of a set of allele-specific markers in breeding populations and germplasm set, thus offering a cost-effective genotyping assay for application in early generation selection. Another study in groundnut was also focused on LLS resistance and identified significant candidate QTLs on three chromosomes, A05, B03, and B05; and three KASP markers were developed that controlled $15 \%$ PVE for LLS resistance (Clevenger et al. 2018). Owing to its ability to permit precise and rapid mapping and discovery of candidate genes, QTL-seq approach is most likely to be frequently used across these legumes in coming years for agronomically important traits.

Despite being an effective approach, the QTL-seq approach sometimes does not deliver expected results because of the trait complexity and in such situations, the second pooled sequencing-based approach, namely "SeqBSA," can be applied for the identification of candidate SNPs in the targeted genomic regions. This approach calculates genome-wide SNP index of both the extreme bulks using QTL-seq pipeline (Takagi et al. 2013a). Seq-BSA has been successfully utilized for the identification of putative SNPs associated with resistance to FW and SMD in pigeonpea (Singh et al. 2016b). This study revealed association of four candidate nsSNPs in four genes with FW resistance and four candidate nsSNPs in three genes with SMD resistance. Further, this study also reported in silico protein analysis and expression profiling leading to identification of two most promising candidate genes namely C.cajan_01839 for SMD resistance and C.cajan_03203 for FW resistance.

The pooled sequencing adopted for QTL-seq and BSAseq can also be used for performing the third pooled sequencing-based approach, namely "Indel-Seq" which mainly focuses on variations identified in insertions and deletions. This approach was successfully deployed in pigeonpea that 
identified 16 InDels affecting 26 putative candidate genes associated with resistance to FW and SMD. Validation of these 16 candidate InDels revealed a significant association of five InDels (three for FW and two for SMD resistance) (Singh et al. 2017). The fourth approach called "MutMap" (Abe et al. 2012) facilitates faster discovery of candidate genes from promising EMS-induced mutants. This approach requires crossing of selected mutant plant for a trait with the wild type, which minimizes the background noise in segregating population. This approach has further modifications wherein it avoids developing any population and just uses mutant and wild-type parents for analysis (MutMap+; Fekih et al. 2013) and performing candidate gene discovery in the gap region which could not be sequenced during genome sequencing (MutMap-Gap; Takagi et al. 2013b).

Similarly, the fifth pooled sequencing-based approach, namely "Bulked segregant RNA-Seq (BSR-Seq)" (Liu et al. 2012), uses the RNA in place of DNA and rest of the analysis is performed similar to the BSA-seq using specialized pipeline. Further, the RNA-seq data for pooled samples for extreme phenotypes were analyzed which helped in discovery of candidate gene for grain protein content (GPC) gene $G P C-B 1$ in wheat (Trick et al. 2012). So far these approaches could not be explored in the legume crops. However, we hope to see application of these approaches in some legume crops like groundnut with large and complex genome.

\section{Molecular breeding product delivery}

Although it used to be considered like a dream to see molecular breeding products in these legume crops, especially when we did not have enough number of markers or good genetic maps about 10 years back. However, collaborative efforts across different organizations fueled with power of sequencing and genotyping technologies have made it possible to deliver several molecular breeding products and deployment of genomic technologies in breeding programs.

In the case of chickpea, genotyping-based selections targeting two QTLs $\left(\mathrm{QTL}_{\mathrm{AR} 1}\right.$ and $\left.\mathrm{QTL}_{\mathrm{AR} 2}\right)$ for Aschochyta blight resistance $(\mathrm{AB})$ accounting for $34 \%$ and $21 \%$ PVE, respectively, led to the development of an advance chickpea line V10 showing marked AB resistance under field conditions (Bouhadida et al. 2013). Consequently, three FWresistant lines and seven $\mathrm{AB}$-resistant lines were selected from the crosses C $214 \times$ WR 315 and C $214 \times$ ILC 3279 , with confirmatory evidence provided by phenotyping (Varshney et al. 2014a). In addition, two more lines, namely Super Annigeri 1 and Improved JG 74 with enhanced resistance race 4 ( $f o c 4$ ), have been developed (Mannur et al. 2018). The effectiveness of MAS was also demonstrated through an increase in the frequency of alleles of the markers (CaER and GAA47) associated with AB resistance driven by the phenotypic selection (Castro et al. 2015). More recently, five resistant lines representing foc 2 gene introgressed into the background of Pusa 256 were reported with the help of foreground selection aided by two SSR markers (TA 37 and TA110) (Pratap et al. 2017). Even for a complex trait like drought tolerance, a total of 29 ILs having marked improvement in root traits like rooting depth, root length density and root dry weight were developed within a short span of three years as a result of marker-assisted improvement of the variety JG 11 targeting the "QTL-hotspot" region (Varshney et al. 2013a). Harboring a number of drought-relevant traits and accounting for up to $58.20 \%$ PVE, this "QTL-hotspot" located on $\mathrm{Ca} 4$ offers a robust genomic region for improving drought tolerance in chickpea (Varshney et al. 2014a). This "QTL-hotspot" is being introgressed in genetic background of several leading and elite varieties at ICRISAT and its collaborating partners.

Markers associated with fertility restoration (Saxena et al. 2018a) and CMS (Sinha et al. 2015) are being used in hybrid pigeonpea breeding programs at ICRISAT. Moreover, a number of markers including SSRs (Saxena et al. 2010; Bohra et al. 2011, 2015b, 2017) and SNPs (unpublished) have been identified/used to facilitate genetic purity testing of pigeonpea hybrids and their parents, thus greatly assisting in hybrid seed production. More recently, a collaborative effort has been initiated by ICRISAT with ICAR-IIPR and other institutions/universities from NARS for accelerated and targeted improvement of ruling mega varieties of pigeonpea in India such as Asha, Maruti, BSMR 736, BSMR 853, PRG 176, UPAS 120, LRG 41, LRG 52, and genotyping-based section is integral part of this initiative.

In groundnut, one SCAR marker was implemented to screen segregating populations and the advanced breeding lines of groundnut for resistance against root-knot nematode [Meloidogyne arenaria (Neal)] in USA. A high correlation was observed between the genotyping and nematode resistance phenotype data with up to $6.3 \%$ discrepancies, which were possibly due to $5.8 \%$ recombination between the resistance gene and the DNA marker (Chu et al. 2007). Application of DNA markers in a backcross breeding program accelerated selection of recombinant progenies carrying nematode resistance and high oleic acid. The selection for nematode resistance was assisted with SCAR, SSR and CAPS markers, while one CAPS marker along with gel-free SNP assay using HybProbe design facilitated selection for high oleic acid. This genotyping-assisted strategy to pyramid nematode resistance with a high $\mathrm{O} / \mathrm{L}$ trait led to the development of "Tifguard High O/L" within 3 years (Chu et al. 2011). A more recent example of marker-assisted improvement of high oleic acid in groundnut includes MAS- and MABC-based selection of genotypes using allele-specific polymerase chain reaction (AS-PCR) and CAPS markers. This allowed early identification of 82 MABC and 387 MAS 
derived ILs, with oleic acid level increased up to 1.1 fold and linoleic acid decreasing up to 1.0 fold (Janila et al. 2016a). In another study, recombinant lines of ICGV 05141 showing up to $44 \%$ higher oleic acid: linoleic acid ratio was obtained as a result of targeted selection for the alleles ahfad $2 a$ and $a h f a d 2 b$ controlling fatty acids contents in groundnut (Bera et al. 2018) at Directorate of Groundnut Research, India.

In addition to nematode resistance and high oleic acid, the molecular breeding has also been successfully conducted for foliar disease resistance, namely rust and LLS in groundnut. The trait mapping efforts identified candidate QTLs (QTL on A03 explaining up to $82.62 \%$ phenotypic variation for rust resistance and up to $67.98 \%$ for LLS while one QTL on A02 for LLS resistance with 40\% PVE) and genes for these two diseases using SSR-based and sequencing approaches (Khedikar et al. 2010; Sujay et al. 2012; Pandey et al. 2017b). These validated diagnostic markers have been deployed in MABC approach, and three popular varieties (ICGV 91114, JL 24 and TAG 24) of groundnut were improved for resistance to both foliar fungal diseases using the resistance donor, GPBD 4 (Varshney et al. 2014b). Furthermore, multi-location evaluation of these ILs showed up to $79 \%$ and $89 \%$ gains in pod yield and haulm yield; and early maturity over their respective recurrent parents, in addition to improved resistance level (Janila et al. 2016b). In a similar way, transfer of QTLs for LLS and rust into a susceptible yet popular variety TMV 2 by SSR markers (GM2009, GM2079, GM 2301, GM1839 and IPAHM103) led researchers to achieve two completely homozygous lines (TMG-29 and TMG-46) with improved resistance and 60\% yield advantage over the recurrent parent (Kolekar et al. 2017). Many of these molecular breeding lines developed through MABC approach for foliar disease resistance (Varshney et al. 2014b) and high oleic acid (Janila et al. 2016a) are under multi-location testing in All India Co-ordinated Research Project on Groundnut (AICRP-G) for further evaluation and release.

To capture the trait variation that is accounted to QTLs with smaller phenotypic variation, marker-assisted recurrent scheme (MARS) scheme has been proposed that allows assembling of superior alleles of different QTLs in a single genotype or in a breeding population based on crossing of genotypes using marker/QTL information (Eathington et al. 2007). In chickpea, MARS was initiated with elite by elite crosses (JG $11 \times$ ICCV 04112 and JG $130 \times$ ICCV 05107) and informed decisions were reached on mating of genotypes using $\mathrm{F}_{3}$ genotyping data and $\mathrm{F}_{5}$ phenotyping data. However, much success could not be achieved through this approach in developing promising lines with desired features.

In recent years, GS approach has become popular to introgress several genes with small additive effects in breeding programs. The increasing availability of massive genetic variants on affordable prices coupled with high-quality phenotyping facilities has provided new avenues to implement GS for improving gains from selections/cycle in crop plants. GS improves genetic gains per unit time through facilitating selection of superior individuals from any breeding population without having any phenotypic record (Crossa et al. 2017). In GS, individuals from training population are scored phenotypically and genotypically to estimate GEBVs, and subsequent selections are exercised on the basis of GEBVs. Superiority of GS over phenotyping- and genotyping-based selection models has been established in simulation as well as empirical studies (Eathington et al. 2007; Ziyomo and Bernardo 2013; Cerrudo et al. 2018).

Regarding GS in these three legume crops, only three reports are available so far and all these studies were conducted in chickpea (Roorkiwal et al. 2016, 2018b; Li et al. 2018). Promising results of GS were evident in chickpea from higher prediction accuracies (up to 0.91) obtained for yield-related traits using six different GS models (Roorkiwal et al. 2016). However, low accuracies were observed for seed yield under rainfed environments. In a more recent GS study in chickpea, Li et al. (2018) suggested incorporating information about the significant markers (GWAS results) to different GS models to increase prediction accuracies. As described above, efforts to apply GS in legume crops have been initiated only recently and this may be due to recent development of cost-effective genotyping platforms in these crops. Excellent reviews have been published on GS in plant breeding that assesses various methods/algorithms being used to calculate prediction accuracies (Lorenz et al. 2011; Heslot et al. 2012; Crossa et al. 2017). Implementing GS for crop improvement faces several challenges such as the relatedness between the phenotyped (training sets) and unphenotyped individuals (testing sets), size of the training sets, and type and number of the DNA markers, and importantly, provisions for integrating $\mathrm{G} \times \mathrm{E} /$ marker $\times$ environment $(\mathrm{M} \times \mathrm{E})$ interactions (Nakaya and Isobe 2018; Crossa et al. 2017). As demonstrated in chickpea, the ability of GS to consider multiple variables simultaneously allowed breeding programs to gain higher prediction accuracies through inclusion of $\mathrm{G} \times \mathrm{E}$ effects (Roorkiwal et al. 2018b). This study also reported higher prediction accuracies with DArT Seq system as compared to the GBS. Similar studies on GS have also been initiated in groundnut at ICRISAT. In brief, we expect to have deployment of GS in several breeding programs in legumes.

In addition to GS, the GS + de novo GWAS model combining the RR-BLUP with markers was reported to be promising for enhancing genetic gains in rice. This strategy is expected to fasten the introduction of novel genetic variations in breeding population (Spindel et al. 2016). Furthermore, haplotype-based GWAS and GS would facilitate the rapid identification and utilization of superior versions of target gene(s)/variations, respectively. For instance, a recent 
GWAS indicated $G m C H X 1$ as the potential candidate conferring salinity tolerance in soybean. In addition, the genotypes belonging to SV-2 haplotype of $G m C H X 1$ were found to be highly tolerant, whereas the other two groups, SV-1 \&amp; SV-3 groups were sensitive (Patil et al. 2016). Similarly, GWAS and haplotype analysis for grain cooking and eating quality traits in rice resulted in the identification of superior and desired haplotypes associated with the trait (Wang et al. 2017). In near future, haplotype-based GS + denovo GWAS will be the promising approach across the crops for targeting superior haplotypes for the development of promising genotypes.

\section{Harnessing genetic diversity}

The urgency to conserve and increase genetic diversity in important food crops is highlighted from the fact that the last century has witnessed a $75 \%$ reduction in crop diversity in farmers' fields, and the climate change is going to reduce it further by nearly $20 \%$ by 2050 (see Massawe et al. 2016). In chickpea, a recent study offers evidence of severe domestication bottleneck, with effective population of cultivated chickpea being 100-fold lesser than that of $C$. reticulatum (von Wettberg et al. 2018). Similarly, the genetic diversity of the cultivated chickpea was found to be 100 times lesser than that of wild chickpea (Cicer reticulatum and $C$. echinospermum). Analysis of landraces and wild relatives in legume crops is greatly assisted by current advances in genomics, phenotyping and computational biology. Analysis of 147 chickpea landraces, housed at the Vavilov Institute of Plant Genetic Resources (VIR), Russia, elucidated genomic basis of a set of "human-selected adaptations." Importantly, these landraces were collected from Turkey and Ethiopia, which represent center of origin and center of diversity, respectively, of chickpea. Combining high-density genotyping data with the historical phenotypic records on these VIR landraces enabled access to "agro islands" or "domestication islands" in chickpea genomes that show significant associations with multiple phenotypes (Plekhanova et al. 2017). Such "genomic gems" containing co-adapted and co-localized gene complexes have also been reported in chickpea on LG4 and LG2 containing multiple genes/QTLs associated with drought and disease resistance, respectively. Earlier, WGRS/RADSeq of 90 Cicer accessions including cultigens, landraces and wild accessions uncovered a large set of 54 genes on LG3 that possibly has been targeted during modern breeding efforts for manipulation of important traits like flowering time (Varshney et al. 2013c).

Similarly in pigeonpea, a genomic region having abundance of MTAs for agronomically important traits was detected on LG9 following re-sequencing of 292 accessions (Varshney et al. 2017). In addition, phylogenetic relationships inferred from WGRS data allowed authors to identify $C$. cajanifolius accession ICP15629, a possible early domesticate with greater agronomic suitability for crop production (Varshney et al. 2017). Accessibility to such genomic "islands" helps in defining "breeding targets" to reintroduce genetic diversity that is lost in modern breeding programs as a consequence of domestication and crop improvement. In view of the escalating problem of habitat loss/degradation, urbanization and shifting land use, systematic efforts are needed to conserve and characterize the germplasm collections that span genetic and geographic breadth. Attempts by Khoury et al. (2015) in this regard are noteworthy with authors analyzing pigeonpea ex situ conservations, identifying the high priority crop wild relatives (CVRs) for further collection and finally, highlighting CWRs with potential traits for use in abiotic stress breeding. A recent survey of chickpea germplasm from "Fertile Crescent" informed by GIS technology led authors to initiative a large-scale introgression breeding program in order to archive broad based genetic populations that harbor potential traits that could facilitate chickpea improvement (von Wettberg et al. 2018). Judicious exploitation of landraces and wild relatives to devise solutions for future needs warrants not only understanding domestication patterns and evolutionary history but also conserving CWRs and accelerating their deployment in pre-breeding programs. Pre-breeding programs will be greatly benefited from GS models that help in prioritizing the accessions for subsequent introgression (Crossa et al. 2017).

In case of groundnut, although the genus Arachis is blessed with enormous genetic variability with 79 wild species and cultivated peanut, the crop faces huge challenge because of the differences in ploidy levels in different species which create big genetic barrier in exchanging the genetic diversity (Sharma et al. 2017). Even if some diploid species have cross-compatibility with the tetraploid species, it requires several generations of selfing for selecting desirable tetraploid recombinants. Therefore, the only solution to this problem is development of synthetic groundnut by doubling the chromosome number of the hybrid derived from two diploid species (Simpson et al. 1993; Mallikarjuna et al. 2011). Once these synthetic groundnuts are developed, then these can be evaluated for traits of interest and crosses can be made for transferring useful genes/alleles into cultivated genetic backgrounds. Successful examples are already available in transferring useful traits such as resistance nematode, late leaf spot and rust resistance and other yield component traits in groundnut (Simpson et al. 2003; Kumari et al. 2014; Sharma et al. 2017; Khera et al. 2018). Nevertheless, large-scale and dedicated efforts are required for generating diverse pre-breeding material from different sources so that the primary gene-pool of groundnut can be enriched with desirable and useful alleles. 


\section{Adopting speed breeding to accelerate genetic gains}

Genomics-assisted breeding improves genetic gains $(\Delta \mathrm{G})$ through enhancing diversity $\left(\sigma^{2} \mathrm{P}\right)$, favorable gene action $\left(h^{2}\right)$ and intensity of selection (i) (Moose and Mumm 2008). Likewise, genetic gains can also be improved by shortening the breeding cycles (L) and this rapid generation advance (RGA) can be achieved through controlling temperature, photoperiod, humidity, and harvesting and germination of immature seeds (Watson et al. 2018; Chiurugwi et al. 2018). Among legume crops, the potential of speeding breeding in reducing generation time in breeding programs has been demonstrated in chickpea (Gaur et al. 2007; Watson et al. 2018), pigeonpea (Saxena et al. 2018a, b, c), and groundnut (O'Connor et al. 2013). In chickpea, 4-6 generations could be obtained within a year with plant growth accelerated with extended photoperiod of $22 \mathrm{~h}$ and a temperature regime of $22 / 17{ }^{\circ} \mathrm{C}$ (Watson et al. 2018). Earlier, early flowering in chickpea was induced following a 24-hr photoperiod, which enabled production of three generations per year with the help of off-season nursery (Gaur et al. 2007). Similarly, the RGA technology in pigeonpea facilitated accelerated production of 3-4 generations per year with 100\% germination reported from immature seeds harvested from 35-day-old plants (Saxena et al. 2017a, b). In groundnut, by integrating speed breeding with single seed descent (SSD) method, O'Connor and colleagues achieved the $F_{2}$ to $F_{5}$ progression within 17 months in greenhouse settings (controlled environment, 24-h photoperiod and optimal temperatures) in comparison with 42 months invested in achieve the same with field-oriented pedigree breeding method. Under green house facility, the emergence rates were found to be $94 \%$ and $91 \%$ in $F_{2}$ and $F_{3}$, respectively, with the corresponding seed recovery rates being $68 \%$ and $74 \%$. Speed breeding in legumes crops is in infancy stage, and the major challenges hampering large-scale adoption of speed breeding in these crops include poor access to the infrastructure including electricity-controlled environment and the lack of trained/ skilled personnel to operate the facility. As suggested by Chiurugwi et al. (2018), these challenges can be met to a great extent with the development of transportable customdesigned chambers or establishment of speed breeding centers at institutes that could lend these services to smaller and resource-poor breeding programs. Similarly, integration of speed breeding with genomics-assisted breeding and highthroughput phenotyping systems will make the cost associated with speed breeding reasonable. However, most critical to this adoption will be identification of the plant growth phases, plant traits and the protocols that help in maximizing the benefits accruing from speed breeding in orphan crops like legumes.

\section{Toward the sequence-based breeding}

While molecular breeding products have been developed using MAS/MABC in major and some legume crops, these approaches are suitable to introgress 1-3 gene combinations. However, stacking large number of genes in one genetic background through backcross or assembling all the genes through forward breeding (early generation screening) utilizing low-cost genotyping system remains a challenging task. For instance, for targeting eight genes, a total of 256 distinct types of $F_{1}$ gametes $\left(2^{n}, \mathrm{n}\right.$ is the number of target genes), 6561 different genotypes in $F_{2}$ population $\left(3^{n}, \mathrm{n}\right.$ is the number of target genes) and 65,536 would be the size of the smallest perfect $F_{2}$ population ( $4 n, n$ is the number of target gene). Genotyping such a large number of individuals with low-throughput marker systems like SSR would be labor-intensive and cost-inefficient, and more importantly, decision for selection of lines for making crosses may not be made prior to the initiation of flowering. Although analyzing a large number of advanced lines in any of the breeding programs is possible with genotyping, the higher costs associated with genotyping may force breeding programs to reduce the number of lines for genotyping. This will, in turn, affect the selection intensity. In addition to above, it is also important to mention that MABC/MAS are good approaches for introgressing one or few traits for which leading/elite/mega varieties have become deficient. However, these approaches are not essentially meant for accelerating genetic gains. In our view, the breeding programs in the post-genome sequencing era need to emphasize more on continuous population improvement as compared to improve few varieties. In this context, sequence-based approaches may be very helpful to integrate into the breeding programs (Fig. 1). A tentative outline of sequence-based breeding is given below.

In the first instance, all possible parental lines for a given breeding program need to be sequenced, if possible, at higher depth. With the assumption of the availability of phenotyping data on these lines for a number of years, if possible, approaches like GWAS or available HapMap based on sequencing of founder genotypes can be used to select suitable parental combinations with higher frequency of superior alleles and with limited number of deleterious alleles. After making significantly large number of crosses with higher number of lines, early generation screening can be made with existing 10 SNP panels for a given crop. Selected lines from such crosses can be subjected for GS analysis by using the training model developed on the germplasm set representatives of the segregating populations. For GS, the best genotyping platform is the fixed SNP array that provides high-quality genotyping data and requires minimal analytical skills. However, from the cost perspectives, 


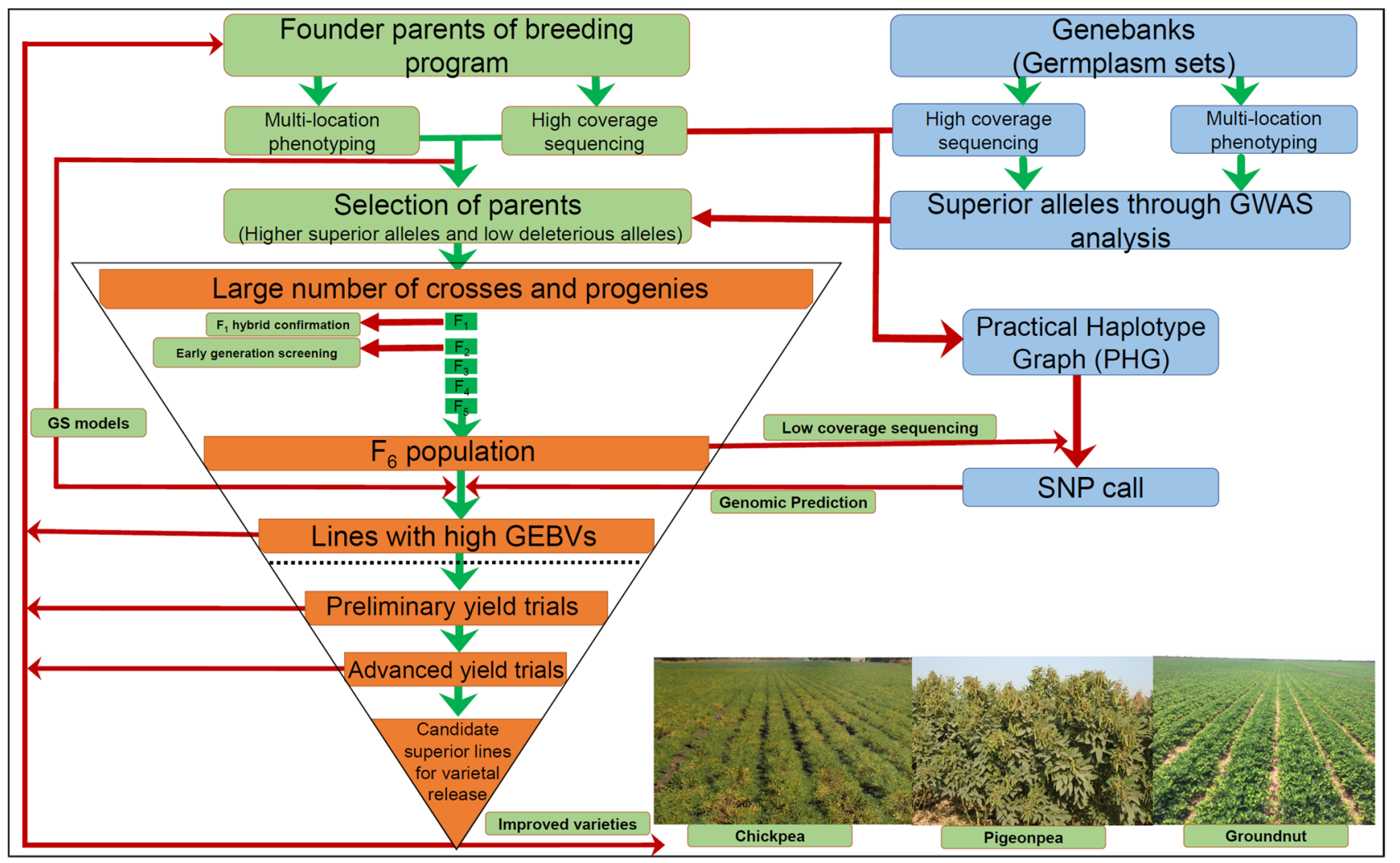

Fig. 1 Flowchart for developing improved legume varieties through sequence-based breeding. The next-generation genomic tools and high-throughput phenotyping systems enable harnessing the superior alleles harbored within vast genetic resources of grain legume crops. Genotyping-based techniques have yielded promising results with the delivery of a variety of molecular breeding products in these crops.

fixed SNP arrays-based genotyping may not be affordable to large-scale breeding programs. In fact, we propose to sequence these segregating progenies at F6/F7 generations at lower coverage like skim sequencing or 384-plex-based GBS-based genotyping so that cost of sequencing per line remains minimal. If this cost is not affordable at present, we assume that this is going to happen very soon. Till that time, we would like to propose use of practical haplotype graph and capture-sequencing of a fixed number of SNP loci on the segregating populations. In brief, sequencing of parental lines, as well as the sequencing data of the other available germplasm lines, can be used for developing practical haplotype graph (PHG) (https://bitbucket.org/bucklerlab/pract icalhaplotypegraph/wiki/Home). Based on this PHG, 20005000 SNP loci, depending on the requirement for deployment of GS in a given crop, can be selected. Subsequently, by using any sequence-based approach, these SNP loci can be assayed using rhAmp (Integrated DNA Technology) or DArTseqLD (https://www.diversityarrays.com/index.php/ technology-and-resources/dartseq/) technologies. Subsequently based on these data, GS breeding can be deployed
In this post genomics era, a shift from genotyping- to sequencingbased assays coupled with our enhanced capacity to integrate multiomics science or a systems biology approach promises to accelerate the genetic gains. Breeder's decisions greatly informed by such modern advances will reflect in higher productivity gains with fewer resources and in less time

on these segregating populations and superior lines with higher GEBVs can be selected. While several of these lines based on preliminary yield trials and advanced yield trials at multiple locations can be taken out for possible candidates for varietal development or use as parent for hybrid breeding programs (e.g., in pigeonpea), we strongly propose use of the best lines from here for integrating in the crossing programs so that next round of breeding populations will be better than the previous round of the populations. We believe by using the sequence-based breeding approach, it will be possible for continuous improvement of populations and accelerate genetic gains at the end of each breeding cycle. This scheme is suitable not only for the legume crops mentioned in this article but in general for all the crops.

\section{Summary and outlook}

Legume crops such as chickpea, pigeonpea and groundnut, though keys for food and nutritional security as well as environmental sustainability, have been lagging as compared to 
major cereal crops in terms of integration of genomic technologies in breeding programs. These crops have achieved now optimum genomic resources required for the faster trait discovery and accelerated breeding. We believe that while MAS/MABC can be continued to improve elite/mega varieties for a few traits, parental selection, early generation screening and GS, ideally all in combination or combination of one and another or even independently should become the integral part of breeding programs. While sequencebased genotyping approaches are already affordable for several applications, several of these approaches or some new approaches will be available in coming future in such a manner that it will be possible to generate genome information in part or full at the rate of US\$ 5 per sample (including DNA extraction). This cost is much cheaper than multi-location evaluation of a line in 2-3 replicates. However, the question is if we will be able to access high-quality and precise phenotyping data at lower cost that is required for trait discovery? Furthermore, do we have standardized phenotyping protocols to score phenotypes for several complex traits in a precise, accurate, high-throughput and cost-effective manner? Similarly, while we are proposing the sequence-based breeding approach here and it is possible to generate genome information for segregating populations in affordable costs, if not now, then very soon, what about data analytical skills in the public breeding programs especially in developing countries? Are our breeding programs well equipped with appropriate field experiment design, bar-code-based labeling of plots, handheld-based data recording and databases containing genotyping and phenotyping? While we may not have answers and solutions for all these questions, we are optimistic that several of these challenges will be addressed in coming years, especially due to several multi-institutional initiatives such as Excellence in Breeding Platform (http:// excellenceinbreeding.org/) and Integrated Breeding Platform (https://www.integratedbreeding.net/).

Having realized above, we are hopeful that the sequencebased breeding approach will come of the age soon. While this approach should be able to help breeding programs for developing faster and superior varieties, it is important that these varieties should reach farmers in reasonable time. In this regard, we need to improve seed delivery system in developing countries (Varshney et al. 2018). Furthermore, farmers need to be trained to adopt appropriate agronomy practices together with better seeds of improved varieties so that they can have higher productivity. Finally, the value chain needs one more step and that is providing farmers' access to markets through digital technologies so that farmers do not just produce more but also can earn more. In summary, we see a huge potential of integration of genomic technologies together with other innovations like speed breeding to accelerate genetic gains not only in breeding and research plots but also to deliver in farmers' fields.
Author contribution statement RKV conceptualized idea, planned MS content and finalized the MS. MKP planned the MS content, coordinated with other co-authors, contributed special sections, brought flow between different sections, and finalized/revised the MS. AB, VKS, MT and RKS planned the MS and contributed special sections.

Acknowledgements The authors are thankful to the Bill and Melinda Gates Foundation (Tropical Legumes I, II and III), United States Agency for International Development (USAID), and MARS-Wrigley of USA; Indian Council of Agricultural Research (ICAR)-National Agricultural Science Funds (NASF), and Department of Biotechnology (DBT) of Government of India and World Bank-assisted Karnataka Watershed Development Project-II (KWDP-II) funded by Government of Karnataka (GoK), India. Authors would like to thank all their colleagues and collaborators at ICRISAT and other organizations for useful discussions about genomics applications in crop improvement. The work reported in this article was undertaken as a part of the CGIAR Research Program on Grain Legumes and Dryland Cereals (GLDC). ICRISAT is a member of the CGIAR.

\section{Compliance with ethical standards}

Conflict of interest Authors declare that they have no conflict of interest.

Open Access This article is distributed under the terms of the Creative Commons Attribution 4.0 International License (http://creativeco mmons.org/licenses/by/4.0/), which permits unrestricted use, distribution, and reproduction in any medium, provided you give appropriate credit to the original author(s) and the source, provide a link to the Creative Commons license, and indicate if changes were made.

\section{References}

Abe A, Kosugi S, Yoshida K, Natsume S, Takagi H, Kanzaki H, Matsumura H, Yoshida K, Mitsuoka C, Tamiru M, Innan H, Cano L, Kamoun S, Terauchi R (2012) Genome sequencing reveals agronomically important loci in rice using MutMap. Nat Biotechnol 30:174-179

Agarwal G, Clevenger J, Pandey MK, Wang H, Shasidhar Y, Chu Y, Fountain JC, Choudhary D, Culbreath AK, Liu X, Huang G, Wang X, Deshmukh R, Holbrook CC, Bertioli DJ, Ozias-Akins P, Jackson SA, Varshney RK, Guo B (2018) High-density genetic map using whole-genome re-sequencing for fine mapping and candidate gene discovery for disease resistance in peanut. Plant Biotechnol J. https://doi.org/10.1111/pbi.12930

Bajaj D, Das S, Badoni S, Kumar V, Singh M, Bansal KC, Tyagi AK, Parida SK (2015) Genome-wide high-throughput SNP discovery and genotyping for understanding natural (functional) allelic diversity and domestication patterns in wild chickpea. Sci Rep 5:12468

Bera SK, Kamdar JH, Kasundra SV, Dash P, Maurya AK, Jasani MD, Chandrashekar AB, Manivannan N, Vasanthi RP, Dobariya KL, Pandey MK, Pasupuleti J, Radhakrishnan T, Varshney RK (2018) Improving oil quality by altering levels of fatty acids through marker-assisted selection of ahfad 2 alleles in peanut (Arachis hypogaea L.). Euphytica 214:162 
Bertioli DJ, Cannon SB, Froenicke L, Huang G, Farmer AD, Cannon EK, Liu X, Gao D, Clevenger J, Dash S, Ren L, Moretzsohn MC, Shirasawa K, Huang W, Vidigal B, Abernathy B, Chu Y, Niederhuth CE, Umale P, Araújo AC, Kozik A, Kim KD, Burow MD, Varshney RK, Wang X, Zhang X, Barkley N, Guimarães PM, Isobe S, Guo B, Liao B, Stalker HT, Schmitz RJ, Scheffler BE, Leal-Bertioli SC, Xun X, Jackson SA, Michelmore R, OziasAkins P (2016) The genome sequences of Arachis duranensis and Arachis ipaensis, the diploid ancestors of cultivated peanut. Nat Genet 48:438-446

Bohra A, Dubey A, Saxena RK, Penmetsa RV, Poornima KN, Kumar N, Farmer AD, Gudipati S, Upadhyaya HD, Gothalwal R, Ramesh S, Singh D, Saxena KB, Kavi Kishor PB, Singh NK, Town CD, Gregory DM, Cook DR, Varshney RK (2011) Analysis of BACend sequences (BESs) and development of BES-SSR markers for genetic mapping and hybrid purity assessment in pigeonpea (Cajanus spp.). BMC Plant Biol 11:56

Bohra A, Sahrawat KL, Kumar S, Joshi R, Parihar AK, Singh U, Singh D, Singh NP (2015a) Genetics- and genomics-based interventions for nutritional enhancement of grain legume crops: status and outlook. J Appl Genet 56:151-161

Bohra A, Singh IP, Yadav AK, Pathak A, Soren KR, Chaturvedi SK, Nadarajan N (2015b) Utility of informative SSR markers in the molecular characterization of cytoplasmic genetic male sterility based hybrid and its parents in pigeonpea. Natl Acad Sci Lett 38:13-19

Bohra A, Jha R, Pandey G, Patil PG, Saxena RK, Singh IP, Singh D, Mishra RK, Mishra A, Singh F, Varshney RK, Singh NP (2017) New hypervariable SSR markers for diversity analysis, hybrid purity testing and trait mapping in Pigeonpea [Cajanus cajan (L.) Millspaugh]. Front Plant Sci 8:1-15

Bouhadida M, Benjannet R, Madrid E, Amri M, Kharrat M (2013) Efficiency of marker-assisted selection in detection of ascochyta blight resistance in Tunisian chickpea breeding lines. Phytopathol Mediterr 52:202-211

Castro P, Rubio J, Madrid E, Fernández-Romero MD, Millán T, Gil J (2015) Efficiency of marker-assisted selection for Ascochyta blight in chickpea. J Agric Sci 153:56-67

Cerrudo D, Cao S, Yuan Y, Martinez C, Suarez EA, Babu R, Zhang X, Trachsel S (2018) Genomic selection outperforms marker assisted selection for grain yield and physiological traits in a maize doubled haploid population across water treatments. Front Plant Sci 9:366

Chen X, Li H, Pandey MK, Yang Q, Wang X, Garg V, Li H, Chi X, Doddamani D, Hong Y, Upadhyaya HD, Guo H, Khan AW, Zhu F, Zhang X, Pan L, Pierce GJ, Zhou G, Krishnamohan KAVS, Chen M, Zhong N, Agarwal G, Li S, Chitikineni A, Zhang G, Sharma S, Chen N, Liu N, Janila P, Li S, Wang M, Wang T, Sun J, Li X, Li C, Wang M, Yu L, Wen S, Singh S, Yang Z, Zhao J, Zhang C, Yu Y, Bi J, Zhang X, Liu Z, Paterson AH, Wang S, Liang X, Varshney RK, Yu S (2016) Draft genome of the peanut A-genome progenitor (Arachis duranensis) provides insights into geocarpy, oil biosynthesis, and allergens. Proc Natl Acad Sci USA 113:6785-6790

Chiurugwi T, Kemp S, Powell W, Hickey LT (2018) Speed breeding orphan crops. Theor Appl Genet. https://doi.org/10.1007/s0012 2-018-3202-7

Chu Y, Holbrook CC, Timper P, Ozias-Akins P (2007) Development of a PCR-based molecular marker to select for nematode resistance in peanut. Crop Sci 47:841-845

Chu Y, Wu CL, Holbrook CC, Tillman BL, Person G, Ozias-Akins P (2011) Marker-assisted selection to pyramid nematode resistance and the high oleic trait in peanut. Plant Genome 4:110-117

Clevenger J, Chu Y, Chavarro C, Botton S, Culbreath AK, Isleib TG, Holbrook CC, Ozias-Akins P (2018) Mapping late leaf spot resistance in peanut (Arachis hypogaea) using QTL-seq reveals markers for marker assisted selection. Front Plant Sci 9:83

Considine MJ (2016) Neglecting legumes has compromised human health and sustainable food production. Nat Plants 2:16112

Crossa J, Pérez-Rodríguez P, Cuevas J, Montesinos-López O, Jarquín D, de los Campos G, Burgueno J, Gonzalez-Camacho JM, PerezElizalde S, Beyene Y, Dreisigacker S, Singh R, Zhang X, Gowda M, Roorkiwal M, Rutkoski J, Varshney RK (2017) Genomic selection in plant breeding: methods, models, and perspectives. Trends Plant Sci 22:961-975

Das S, Upadhyaya HD, Bajaj D, Kujur A, Badoni S, Laxmi Kumar V, Tripathi S, Gowda CL, Sharma S, Singh S, Tyagi AK, Parida SK (2015) Deploying QTL-seq for rapid delineation of a potential candidate gene underlying major trait-associated QTL in chickpea. DNA Res 22:193-203

Deokar AA, Ramsay L, Sharpe AG, Diapari M, Sindhu A, Bett K, Warkentin TD, Taran B (2014) Genome wide SNP identification in chickpea for use in development of a high density genetic map and improvement of chickpea reference genome assembly. BMC Genom 15:708

Deokar A, Sagi M, Daba K, Taran B (2018) QTL sequencing strategy to map genomic regions associated with resistance to Ascochyta blight in chickpea. Plant Biotechnol J. https://doi.org/10.1111/ pbi. 12964

Eathington SR, Crosbie TM, Edwards MD, Reiter RS, Bull JK (2007) Molecular markers in a commercial breeding program. Crop Sci 47:154-163

Elshire RJ, Glaubitz JC, Sun Q, Poland JA, Kawamoto K, Buckler ES, Mitchell SE (2011) A robust, simple genotyping-by-sequencing (GBS) approach for high diversity species. PLoS ONE 6(5):e19379

Fekih R, Takagi H, Tamiru M, Abe A, Natsume S (2013) MutMap+ genetic mapping and mutant identification without crossing in rice. PLoS ONE 10:e68529

Foyer CH, Lam H-M, Nguyen HT, Kadambot HMS, Varshney RK, Colmer TD, Cowling W, Bramley H, Mori TA, Hodgson JM, Cooper JW, Miller AJ, Kunert K, Vorster J, Cullis C, Ozga JA, Wahlqvist ML, Liang Y, Shou H, Shi K, Yu J, Fodor N, Kaiser BN, Wong FL, Valliyodan B, Considine MJ (2016) Neglecting legumes has compromised human health and sustainable food production. Nat Plants 2:16112

Gaur P, Samineni S, Laxmipathi Gowda C, Rao BV (2007) Rapid generation advancement in chickpea. SAT eJ 3:1-3

Golicz AA, Bayer PE, Edwards D (2015) Skim-based genotyping by sequencing. Methods Mol Biol 1245:257-270

Heslot N, Sorrells ME, Jannink JL, Yang HP (2012) Genomic selection in plant breeding: a comparison of models. Crop Sci 52:146-160

Huang X, Feng Q, Qian Q, Quaing Z, Wang L, Wang A, Guan J, Fan D, Weng Q, Huang T, Dong G, Sang T, Han B (2009) Highthroughput genotyping by whole-genome resequencing. Genome Res 19:1068-1076

Jaganathan D, Thudi M, Kale S, Azam S, Roorkiwal M, Gaur PM, Kishor PB, Nguyen H, Sutton T, Varshney RK (2015) Genotyping-by-sequencing based intra-specific genetic map refines a "QTL-hotspot" region for drought tolerance in chickpea. Mol Genet Genom 290:559-571

Janila P, Pandey MK, Shasidhar Y, Variath MT, Sriswathi M, Khera P, Manohar SS, Nagesh P, Vishwakarma MK, Mishra GP, Radhakrishnan T, Manivannan N, Dobariya KL, Vasanthi RP, Varshney RK (2016a) Molecular breeding for introgression of fatty acid desaturase mutant alleles ( $a h F A D 2 A$ and $a h F A D 2 B)$ enhances oil quality in high and low oil containing peanut genotypes. Plant Sci 242:203-213

Janila P, Pandey MK, Manohar SS, Variath MT, Nallathambi P, Nadaf HL, Sudini H, Varshney RK (2016b) Foliar 
fungal disease-resistant introgression lines of groundnut (Arachis hypogaea $\mathrm{L}$.) record higher pod and haulm yield in multilocation testing. Plant Breed 135:355-366

Kale SM, Jaganathan J, Ruperao P, Chen C, Punna R, Kudapa H, Thudi M, Roorkiwal M, Mohan AVSKK, Doddamani D, Garg V, Kavi Kishor PB, Gaur PM, Nguyen HT, Batley J, Edwards D, Sutton T, Varshney RK (2015) Prioritization of candidate genes in QTLhotspot region for drought tolerance in chickpea (Cicer arietinum L.). Sci Rep 5:15296

Kawashima CG, Guimarães GA, Nogueira SR, MacLean D, Cook DR, Steuernagel B, Baek J, Bouyioukos C, Melo Bdo V, Tristão G, de Oliveira JC, Rauscher G, Mittal S, Panichelli L, Bacot K, Johnson E, Iyer G, Tabor G, Wulff BB, Ward E, Rairdan GJ, Broglie KE, Wu G, van Esse HP, Jones JD, Brommonschenkel SH (2016) A pigeonpea gene confers resistance to Asian soybean rust in soybean. Nat Biotechnol 34(6):661-665

Khedikar YP, Gowda MVC, Sarvamangala C, Patgar KV, Upadhyaya HD, Varshney RK (2010) A QTL study on late leaf spot and rust revealed one major QTL for molecular breeding for rust resistance in groundnut (Arachis hypogaea L.). Theor Appl Genet 121:971-984

Khera P, Pandey MK, Mallikarjuna N, Sriswathi M, Roorkiwal M, Janila P, Sharma S, Shilpa S, Sudini H, Guo B, Varshney RK (2018) Advanced backcross QTL analysis for disease resistance, oil quality and yield component traits revealed genetic imprints of domestication in groundnut (Arachis hypogaea L.). Mol Genet Genom. https://doi.org/10.1007/s00438-018-1511-9

Khoury CK, Castañeda-Alvarez NP, Achicanoy HA, Sosa CC, Bernau V, Kassa MT, Norton SL, von der Maesen LJG, Upadhyaya HD, Ramirez-Villegas J, Jarvis A, Struik PC (2015) Crop wild relatives of pigeonpea [Cajanus cajan (L.) Millsp.]: distributions, ex situ conservation status, and potential genetic resources for abiotic stress tolerance. Biol Conserv 184:259-270

Kolekar RM, Sukruth M, Nadaf HL, Motagi BN, Lingaraju S, Patil PV, Bhat RS (2017) Marker-assisted backcrossing to develop foliar disease resistant genotypes in TMV 2 variety of peanut (Arachis hypogaea L.). Plant Breed 136:948-953

Kujur A, Bajaj D, Upadhyaya H, Das S, Ranjan R, Shree T, Saxena MS, Badoni S, Kumar V, Tripathi S, Gowda CL, Sharma S, Singh S, Tyagi AK, Parida SK (2015) A genome-wide SNP scan accelerates trait-regulatory genomic loci identification in chickpea. Sci Rep 5:11166

Kumar V, Khan AW, Saxena RK, Garg V, Varshney RK (2016) First generation HapMap in Cajanus spp. reveals untapped variations in parental lines of mapping populations. Plant Biotechnol $\mathbf{J}$ 14:1673-1681

Kumari V, Gowda MVC, Tasiwal V, Pandey MK, Bhat RS, Mallikarjuna N, Upadhyaya HD, Varshney RK (2014) Diversification of primary gene pool through introgression of resistance allele for foliar diseases from synthetic amphidiploids to cultivated groundnut (Arachis hypogaea L.). Crop J 2(2-3):110-119

Li Y, Ruperao P, Batley J, Edwards D, Khan T, Colmer TD, Pang J, Siddique KHM, Sutton T (2018) Investigating drought tolerance in chickpea using genome-wide association mapping and genomic selection based on whole-genome resequencing data. Front Plant Sci 9:190

Liu S, Yeh C-T, Tang HM, Nettleton D, Schnable PS (2012) Gene mapping via bulked segregant RNA-Seq (BSR-Seq). PLoS ONE 7:36406

Lorenz AJ, Chao S, Asoro FG, Heffner EL, Hayashi T, Iwata H, Smith KP, Sorrels ME, Jannink J-C (2011) Genomic selection in plant breeding: knowledge and prospects. Adv Agron 110:77-123

Mallikarjuna N, Senthilvel S, Hoisington D (2011) Development of new sources of tetraploid Arachis to broaden the genetic base of cultivated groundnut (Arachis hypogaea L.). Genet Resour Crop Evol 58:889-907
Mannur DM, Babbar A, Thudi M, Sabbavarapu MM, Roorkiwal M, Yeri SB, Bansal VP, Jayalakshmi SK, Yadav SS, Rathore A, Chamarthi SK, Mallikarjuna BP, Gaur PM, Varshney RK (2018) Super annigeri 1 and improved JG 74: two fusarium wilt resistant introgression lines developed using marker-assisted backcrossing approach in chickpea (Cicer arietinum L.). Mol Breed. https:// doi.org/10.1007/s11032-018-0908-9

Massawe F, Mayes S, Cheng A (2016) Crop diversity: an unexploited treasure trove for food security. Trends Plant Sci 21:P365-P368

Michelmore RW, Paran I, Kesseli RV (1991) Identification of markers linked to disease-resistance genes by bulked segregant analysis: a rapid method to detect markers in specific genomic regions by using segregating populations. Proc Natl Acad Sci USA 88:9828-9832

Moose SP, Mumm RH (2008) Molecular plant breeding as the foundation for 21 st century crop improvement. Plant Physiol 147:969-977

Nakaya A, Isobe SN (2018) Will genomic selection be a practical method for plant breeding? Ann Bot 110(6):1303-1316

O'Connor DJ, Wright GC, Dieters MJ, George DL, Hunter MN, Tatnell JR, Fleischfresser DB (2013) Development and application of speed breeding technologies in a commercial peanut breeding program. Peanut Sci 40:107-114

Pandey MK, Monyo E, Ozias-Akins P, Liang X, Guimarães P, Nigam SN, Upadhyaya HD, Janila P, Zhang X, Guo B, Cook DR, Bertioli DJ, Michelmore R, Varshney RK (2012) Advances in Arachis genomics for peanut improvement. Biotechnol Adv 30:639-651

Pandey MK, Roorkiwal M, Singh VK, Ramalingam A, Kudapa H, Thudi M, Chitikineni A, Rathore A, Varshney RK (2016) Emerging genomic tools for legume breeding: current status and future prospects. Front Plant Sci 7:455

Pandey MK, Agarwal G, Kale SM, Clevenger J, Nayak SN, Sriswathi M, Chitikineni A, Chavarro C, Chen X, Upadhyaya HD, Vishwakarma MK, Leal-Bertioli S, Liang X, Bertioli DJ, Guo B, Jackson SA, Ozias-Akins P, Varshney RK (2017a) Development and evaluation of a high density genotyping 'Axiom_Arachis' array with $58 \mathrm{~K}$ SNPs for accelerating genetics and breeding in groundnut. Sci Rep 7:40577

Pandey MK, Khan AW, Singh VK, Vishwakarma MK, Shasidhar Y, Kumar V, Garg V, Bhat RS, Chitikineni A, Janila P, Guo B, Varshney RK (2017b) QTL-seq approach identified genomic regions and diagnostic markers for rust and late leaf spot resistance in groundnut (Arachis hypogaea L.). Plant Biotechnol J 15(8):927-941

Patil G, Do T, Vuong TD, Valliyodan B, Lee JD, Chaudhary J, Shannon JG, Nguyen HT (2016) Genomic-assisted haplotype analysis and the development of high-throughput SNP markers for salinity tolerance in soybean. Sci Rep 6:19199

Pavan S, Lotti C, Marcotrigiano AR, Mazzeo R, Bardaro N, Bracuto V, Ricciardi F, Taranto F, D'Agostino N, Schiavulli A, De Giovanni C, Montemurro C, Sonnante G, Ricciardi L (2017) A distinct genetic cluster in cultivated chickpea as revealed by genomewide marker discovery and genotyping. Plant Genome 10:1-9

Plekhanova E, Vishnyakova MA, Bulyntsev S, Chang PL, CarrasquillaGarcia N, Negash K, von Wettberg E, Noujdina N, Cook DR, Samsonova MG, Nuzhdin SV (2017) Genomic and phenotypic analysis of Vavilov's historic landraces reveals the impact of environment and genomic islands of agronomic traits. Sci Rep 7:4816

Pratap A, Chaturvedi SK, Tomar R, Rajan N, Malviya N, Thudi M, Saabale PR, Prajapati U, Varshney RK, Singh NP (2017) Markerassisted introgression of resistance to fusarium wilt race 2 in Pusa 256, an elite cultivar of desi chickpea. Mol Genet Genom 292:1237-1245 
Rasheed A, Hao Y, Xia X, Khan A, Xu Y, Varshney RK, He Z (2017) Crop breeding chips and genotyping platforms: progress, challenges and perspectives. Mol Plant 10:1047-1064

Roorkiwal M, Rathore A, Das RR, Singh MK, Jain A, Srinivasan S, Gaur PM, Chellapilla B, Tripathi S, Li Y, Hickey JM, Lorenz A, Sutton T, Crossa J, Jannink JL, Varshney RK (2016) Genomeenabled prediction models for yield related traits in chickpea. Front Plant Sci 7:1666

Roorkiwal M, Jain A, Kale SM, Doddamani D, Chitikineni A, Thudi M, Varshney RK (2018a) Development and evaluation of high density SNP array (Axiom ${ }^{\circledR}$ CicerSNP Array) for high resolution genetic mapping and breeding applications in chickpea. Plant Biotechnol J 16:890-901

Roorkiwal M, Jarquin D, Singh MK, Gaur PM, Bharadwaj C, Rathore A, Howard R, Srinivasan S, Jain A, Garg V, Kale S, Chitikineni A, Tripathi S, Jones E, Robbins KR, Crossa J, Varshney RK (2018b) Genomic-enabled prediction models using multi-environment trials to estimate the effect of genotype $\times$ environment interaction on prediction accuracy in chickpea. Sci Rep 8:11701

Ruperao P, Chan CK, Azam S, Karafiátová M, Hayashi S, Cížková J, Saxena RK, Simková H, Song C, Vrána J, Chitikineni A, Visendi P, Gaur PM, Millán T, Singh KB, Taran B, Wang J, Batley J, Doležel J, Varshney RK, Edwards D (2014) A chromosomal genomics approach to assess and validate the desi and kabuli draft chickpea genome assemblies. Plant Biotechnol J 12:778-786

Saxena RK, Prathima C, Saxena KB, Hoisington DA, Singh NK, Varshney RK (2010) Novel SSR markers for polymorphism detection in pigeonpea (Cajanus spp.). Plant Breed 129:142-148

Saxena RK, Kale SM, Kumar V, Parupalli S, Joshi S, Singh VK, Garg V, Das RR, Sharma M, Yamini KN, Ghanta A, Rathore A, Sameerkumar CV, Saxena KB, Varshney RK (2017a) Genotyping-by-sequencing of three mapping populations for identification of candidate genomic regions for resistance to sterility mosaic disease in pigeonpea. Sci Rep 7:1813

Saxena RK, Singh VK, Kale SM, Tathineni R, Parupalli S, Kumar V, Garg V, Das RR, Sharma M, Yamini KN, Muniswamy S, Ghanta A, Rathore A, Kumar CVS, Saxena KB, Kishor PBK, Varshney RK (2017b) Construction of genotyping-by-sequencing based high-density genetic maps and QTL mapping for fusarium wilt resistance in pigeonpea. Sci Rep 7:1911

Saxena RK, Patel K, Sameer Kumar CV, Tyagi K, Saxena KB, Varshney RK (2018a) Molecular mapping and inheritance of restoration of fertility $(R f)$ in A4 hybrid system in pigeonpea (Cajanus cajan (L.) Millsp.). Theor Appl Genet 131:1605-1614

Saxena RK, Rathore A, Bohra A, Yadav P, Das RR, Khan AW, Singh VK, Chitikineni A, Singh IP, Sameer Kumar CV, Saxena KB, Varshney RK (2018b) Development and application of high density Axiom ${ }^{\circledR}$ Cajanus SNP Array with 56 K SNPs to understand the genome architecture of released cultivars and founder genotypes for redefining future pigeonpea breeding programs. Plant Genome. https://doi.org/10.3835/plantgenome2018.01.0005

Saxena RK, Patel K, Kumar CVS, Tyagi K, Saxena KB, Varshney RK (2018c) Molecular mapping and inheritance of restoration of fertility $(R f)$ in $\mathrm{A} 4$ hybrid system in pigeonpea (Cajanus cajan (L.) Millsp.). Theor Appl Genet 131:1605-1614

Sharma S, Pandey MK, Sudini HK, Mallikarjuna N, Upadhyaya HD, Varshney RK (2017) Harnessing genetic diversity of wild Arachis species for genetic enhancement of cultivated peanut. Crop Sci 57(1):1-11

Simpson CE, Starr JL, Nelson SC, Woodard KE, Smith OD (1993) Registration of TxAG-6 and TxAG-7 peanut germplasm. Crop Sci 33:1418

Simpson CE, Starr JL, Church GT, Burow MD, Paterson AH (2003) Registration of 'Nema TAM' peanut. Crop Sci 43:1561
Singh VK, Khan AW, Jaganathan D, Thudi M, Roorkiwal M, Takagi H, Garg V, Kumar V, Chitikineni A, Gaur PM, Sutton T, Terauchi R, Varshney RK (2016a) QTL-seq for rapid identification of candidate genes for 100-seed weight and root/total plant dry weight ratio under rainfed conditions in chickpea. Plant Biotechnol J 14:2110-2119

Singh VK, Khan AW, Saxena RK, Kumar V, Kale SM, Sinha P, Chitikineni A, Pazhamala LT, Garg V, Sharma M, Sameer Kumar CV, Parupalli S, Vechalapu S, Patil S, Muniswamy S, Ghanta A, Yamini KN, Dharmaraj PS, Varshney RK (2016b) Nextgeneration sequencing for identification of candidate genes for Fusarium wilt and sterility mosaic disease in pigeonpea (Cajanus cajan). Plant Biotechnol J 14:1183-1194

Singh VK, Khan AW, Saxena RK, Sinha P, Kale SM, Parupalli S, Kumar V, Chitikineni A, Vechalapu S, Sameer Kumar CV, Sharma M, Ghanta A, Yamini KN, Muniswamy S, Varshney RK (2017) Indel-seq: a fast-forward genetics approach for identification of trait-associated putative candidate genomic regions and its application in pigeonpea (Cajanus cajan). Plant Biotechnol J 15:906-914

Sinha P, Saxena KB, Saxena RK, Singh VK, Suryanarayana V, Sameer Kumar CV, Katta MAVS, Khan AW, Varshney RK (2015) Association of $n a d 7 a$ gene with cytoplasmic male sterility in pigeonpea. Plant Genome 8:2

Spindel JE, Begum H, Akdemir D, Collard B, Redoña E, Jannink J, McCouch S (2016) Genome-wide prediction models that incorporate de novo GWAS are a powerful new tool for tropical rice improvement. Heredity 116:395-408

Sujay V, Gowda MVC, Pandey MK, Bhat RS, Khedikar YP, Nadaf HL, Gautami B, Sarvamangala C, Lingaraju S, Radhakrishan T, Knapp SJ, Varshney RK (2012) Quantitative trait locus analysis and construction of consensus genetic map for foliar disease resistance based on two recombinant inbred line populations in cultivated groundnut (Arachis hypogaea L.). Mol Breed 32(2):773-788

Takagi H, Abe A, Yoshida K, Kosugi S, Natsume S, Mitsuoka C, Uemura A, Utsushi H, Tamiru M, Takuno S, Innan H, Cano LM, Kamoun S, Terauchi R (2013a) QTL-seq: rapid mapping of quantitative trait loci in rice by whole genome resequencing of DNA from two bulked populations. Plant J 74:174-183

Takagi H, Uemura A, Yaegashi H, Tamiru M, Abe A, Mitsuoka C, Utsushi H, Natsume S, Kanzaki H, Matsumura H, Saitoh H, Yoshida K, Cano LM, Kamoun S, Terauchi R (2013b) MutMapGap: whole-genome resequencing of mutant $\mathrm{F}_{2}$ progeny bulk combined with de novo assembly of gap regions identifies the rice blast resistance gene Pii. New Phytol 200:276-283

Thudi M, Upadhyaya HD, Rathore A, Pooran Mal Gaur PM, Krishnamurthy L, Roorkiwal M, Nayak SN, Chaturvedi SK, Basu PS, Gangarao NVPR, Fikre A, Kimurto P, Sharma PC, Varshney RK (2014) Genetic dissection of drought and heat tolerance in chickpea through genome-wide and candidate gene-based association mapping approaches. PLoS ONE 12:e0175609

Thudi M, Chitikineni Liu X, He W, Roorkiwal M, Yang W, Jian J, Doddamani D, Gaur PM, Rathore A, Samineni S, Saxena RK, Xu D, Singh NP, Chaturvedi SK, Zhang G, Wang J, Datta SK, Xu X, Varshney RK (2016a) Recent breeding programs enhanced genetic diversity in both desi and kabuli varieties of chickpea (Cicer arietinum $\mathrm{L}$ ). Sci Rep 6:38636

Thudi M, Khan AW, Kumar V, Gaur PM, Katta AVSK, Garg V, Roorkiwal M, Samineni S, Varshney RK (2016b) Whole genome resequencing reveals genome wide variations among parental lines of mapping populations in chickpea (Cicer arietinum). BMC Plant Biol 16:10

Trick M, Adamski NM, Mugford SG, Jiang CC, Febrer M, Uauy C (2012) Combining SNP discovery from next-generation 
sequencing data with bulked segregant analysis (BSA) to finemap genes in polyploidy wheat. BMC Plant Biol 12:14

Upadhyaya HD, Bajaj D, Das S, Saxena MS, Badoni S, Kumar V, Tripathi S, Gowda CL, Sharma S, Tyagi AK, Parida SK (2015) A genome-scale integrated approach aids in genetic dissection of complex flowering time trait in chickpea. Plant Mol Biol 89:403-420

van Berkum NL, Lieberman-Aiden E, Williams L, Imakaev M, Gnirke A, Mirny LA, Dekker J, Lander ES (2010) Hi-C: a method to study the three-dimensional architecture of genomes. J Vis Exp 39:1869

Varshney RK (2016) Exciting journey of 10 years from genomes to fields and markets: some success stories of genomics-assisted breeding in chickpea, pigeonpea and groundnut. Front Pl Sci 242:98-107

Varshney RK, Chen W, Li Y, Bharti AK, Saxena RK, Schlueter JA, Donoghue MTA, Azam S, Fan G, Whaley AM, Farmer AD, Sheridan J, Iwata A, Tuteja R, Penmetsa RV, Wu W, Upadhyaya HD, Yang SP, Shah T, Saxena KB, Michael T, McCombie WR, Yang B, Zhang G, Yang H, Wang J, Spillane C, Cook DR, May GD, Xu X, Jackson SA (2012) Draft genome sequence of pigeonpea (Cajanus cajan), an orphan legume crop of resource-poor farmers. Nat Biotechnol 30:83-89

Varshney RK, Gaur PM, Chamarthi SK, Krishnamurthy L, Tripathi S, Kashiwagi J, Samineni S, Singh VK, Thudi M, Jaganathan D (2013a) Fast-track introgression of 'QTL-hotspot' for root traits and other drought tolerance traits in JG 11, an elite and leading variety of chickpea. Plant Genome 6:1-9

Varshney RK, Murali Mohan S, Gaur PM, Gangarao NVPR, Pandey MK, Bohra A, Sawargaonkar SL, Chitikineni A, Kimurto PK, Janila P, Saxena KB, Fikre A, Sharma M, Rathore A, Pratap A, Tripathi S, Datta S, Chaturvedi SK, Mallikarjuna N, Anuradha G, Babbar A, Choudhary AK, Mhase MB, Bharadwaj Ch, Mannur DM, Harer PN, Guo B, Liang X, Nadarajan N, Gowda CL (2013b) Achievements and prospects of genomics-assisted breeding in three legume crops of the semi-arid tropics. Biotechnol Adv 31:1120-1134

Varshney RK, Song C, Saxena RK, Azam S, Yu S, Sharpe A, Cannon S, Baek J, Rosen BD, Ta'ran B, Millan T, Zhang X, Ramsay LD, Iwata A, Wang Y, Nelson W, Farmer AD, Gaur PM, Soderlund C, Penmetsa RV, Xu C, Bharti AK, He W, Winter P, Zhao S, Hane JK, Carrasquilla-Garcia N, Condie JA, Upadhyaya HD, Luo MC, Thudi M, Gowda CLL, Singh NP, Lichtenzveig J, Gali KK, Rubio J, Nadarajan N, Dolezel J, Bansal KC, Xu X, Edwards D, Zhang G, Kahl G, Gil J, Singh KB, Datta SK, Jackson SA, Wang J, Cook DR (2013c) Draft genome sequence of chickpea (Cicer arietinum) provides a resource for trait improvement. Nat Biotechnol 31:240-246

Varshney RK, Mohan SM, Gaur PM, Chamarthi SK, Singh VK, Samineni S, Swapan N, Sharma M, Singh S, Kaur L, Pande S (2014a) Marker assisted backcrossing to introgress resistance to fusarium wilt race 1 and ascochyta blight in C 214, an elite cultivar of chickpea. Plant Genome 7:1-11

Varshney RK, Pandey MK, Pasupuleti J, Nigam SN, Sudini H, Gowda MVC, Sriswathi M, Radhakrishnan T, Manohar SS, Nagesh P (2014b) Marker-assisted introgression of a QTL region to improve rust resistance in three elite and popular varieties of peanut (Arachis hypogaea L.). Theor Appl Genet 127:1771-1781
Varshney RK, Kudapa H, Pazhamala L, Chitikineni A, Thudi M, Bohra A, Gaur PM, Janila P, Fikre A, Kimurto P, Ellis N (2015) Translational genomics in agriculture: some examples in grain legumes. Crit Rev Plant Sci 34:169-194

Varshney RK, Saxena RK, Upadhyaya HD, Khan AW, Yu Y, Kim C, Rathore A, Kim D, Kim J, An S, Kumar V, Anuradha G, Yamini KN, Zhang W, Muniswamy S, Kim JS, Penmetsa RV, von Wettberg E, Datta SK (2017) Whole-genome resequencing of 292 pigeonpea accessions identifies genomic regions associated with domestication and agronomic traits. Nat Genet 49:1082-1088

Varshney RK, Thudi M, Pandey MK, Tardieu F, Ojiewo C, Vadez V, Whitbread AM, Siddique KHM, Nguyen HT, Carberry PS, Bergvinson D (2018) Accelerating genetic gains in legumes for the development of prosperous smallholder agriculture: integrating genomics, phenotyping, systems modelling and agronomy. J Exp Bot 69:3293-3312

Verma S, Gupta S, Bandhiwal N, Kumar T, Bharadwaj C, Bhatia S (2015) High-density linkage map construction and mapping of seed trait QTLs in chickpea (Cicer arietinum L.) using genotyping-by-sequencing (GBS). Sci Rep 5:17512

von Wettberg EJB, Chang PL, Başdemir F, Carrasquila-Garcia N, Korbu LB, Moenga SM, Bedada G, Greenlon A, Moriuchi KS, Singh V, Cordeiro MA, Noujdina NV, Dinegde KN, Sani SGAS, Getahun T, Vance L, Bergmann E, Lindsay D, Mamo BE, Warschefsky EJ, Dacosta-Calheiros E, Marques E, Yilmaz MA, Cakmak A, Rose J, Migneault A, Krieg CP, Saylak S, Temel H, Friesen ML, Siler E, Akhmetov Z, Ozcelik H, Kholova J, Can C, Gaur P, Yildirim M, Sharma H, Vadez V, Tesfaye K, Woldemedhin AF, Taran B, Aydogan A, Bukun B, Penmetsa RV, Berger J, Kahraman A, Nuzhdin SV, Cook DR (2018) Ecology and genomics of an important crop wild relative as a prelude to agricultural innovation. Nat Commun 9:649

Wang X, Pang Y, Zhang J, Wu Z, Chen K, Ali J, Ye G, Xu J, Li Z (2017) Genome-wide and gene-based association mapping for rice eating and cooking characteristics and protein content. Sci Rep. 7(1): 17203

Watson A, Ghosh S, Williams MJ, Cuddy WS, Simmonds J, Rey M-D, Hatta MAM, Hinchliffe A, Steed A, Reynolds D, Adamski NM, Breakspear A, Dixon LE, Riaz A, Martin W, Ryan M, Edwards D, Batley J, Raman H, Carter J, Rogers C, Moore G, Harwood W, Nicholson P, Dieters MJ, DeLacy IH, Zhou J, Uauy C, Boden SA, Park RF, Wulff BBH, Hickey LT (2018) Speed breeding is a powerful tool to accelerate crop research and breeding. Nat Plants 4:23-29

Zhou X, Xia Y, Ren X, Chen Y, Huang L, Huang S, Liao B, Lei Y, Yan L, Jiang H (2014) Construction of a SNP-based genetic linkage map in cultivated peanut based on large scale marker development using next-generation double-digest restriction-siteassociated DNA sequencing (ddRADseq). BMC Genom 15:351

Zhou X, Xia Y, Liao J, Liu K, Li Q, Dong Y, Ren X, Chen Y, Huang Y, Liao B, Lei Y, Yan L, Jiang H (2016) Quantitative trait locus analysis of late leaf spot resistance and plant-type-related traits in cultivated peanut (Arachis hypogaea L.) under multi-environments. PLoS ONE 11:0166873

Ziyomo C, Bernardo R (2013) Drought tolerance in maize: indirect selection through secondary traits versus genome wide selection. Crop Sci 53:1269-1275 